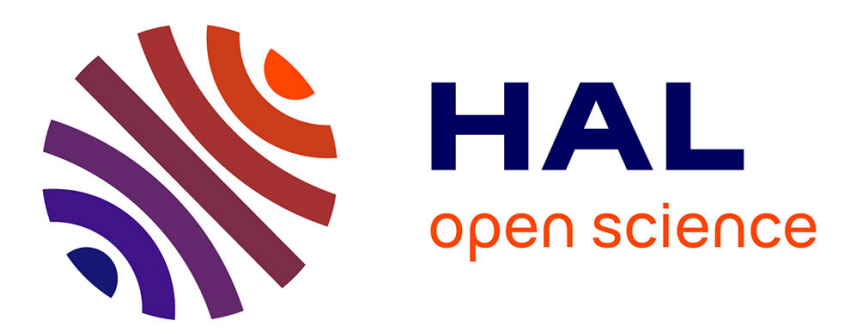

\title{
Inelastic deformation of highly aligned dry-spun thermoplastic polyurethane elastomer microfibres
}

Chin Joo Tan, Andri Andriyana, Bee Chin Ang, Grégory Chagnon

\section{To cite this version:}

Chin Joo Tan, Andri Andriyana, Bee Chin Ang, Grégory Chagnon. Inelastic deformation of highly aligned dry-spun thermoplastic polyurethane elastomer microfibres. Materials Research Express, 2018, 5 (12), pp.125301. hal-01974091

\section{HAL Id: hal-01974091 \\ https://hal.science/hal-01974091}

Submitted on 30 Jan 2019

HAL is a multi-disciplinary open access archive for the deposit and dissemination of scientific research documents, whether they are published or not. The documents may come from teaching and research institutions in France or abroad, or from public or private research centers.
L'archive ouverte pluridisciplinaire HAL, est destinée au dépôt et à la diffusion de documents scientifiques de niveau recherche, publiés ou non, émanant des établissements d'enseignement et de recherche français ou étrangers, des laboratoires publics ou privés. 
Inelastic deformation of highly aligned dry-spun thermoplastic polyurethane elastomer microfibres

Chin Joo Tan ${ }^{1}$, Andri Andriyana ${ }^{1, *}$, Bee Chin Ang ${ }^{2}$, Grégory Chagnon ${ }^{3}$

${ }^{1}$ Centre of Advanced Materials, Department of Mechanical Engineering, Faculty of Engineering, University of Malaya, 50603 Kuala Lumpur, Malaysia

${ }^{2}$ Centre of Advanced Materials, Department of Chemical Engineering, Faculty of Engineering, University of Malaya, 50603 Kuala Lumpur, Malaysia

${ }^{3}$ Université Grenoble Alpes, CNRS, CHU Grenoble Alpes, Grenoble INP, TIMC-IMAG, F38000 Grenoble, France.

*Corresponding Author. Email: andri.andriyana@um.edu.myＯRCID: 0000-0001-7039-2044 


\begin{abstract}
The present study focuses on the fabrication and mechanical responses of highly aligned thermoplastic polyurethane microfibres. A facile dry spinning assisted by an electrical field technique was used to fabricate these microfibres. The surface morphology of the microfibres were inspected under a scanning electron microscope, while their mechanical responses were probed using universal tensile machine. The mechanical tests include uniaxial monotonic, cyclic with increasing maximum strain and relaxation tensile tests using two different strain rates: $0.1 \mathrm{~s}^{-}$ ${ }^{1}$ and $0.001 \mathrm{~s}^{-1}$. According to the surface morphology study, the fibres are highly aligned with the diameter of $2.80 \pm 0.06 \mu \mathrm{m}$ and without beads. As for mechanical tests, the fibres show inelastic mechanical responses such as hysteresis, stress-softening, stress relaxation and residual strain. Except for its nearly linear stress-strain response before reaching ultimate tensile strength, it appears that the thermoplastic polyurethane elastomer microfibres exhibit general features commonly found in bulk elastomers. The findings in this study are expected to provide a basis for the modelling of the mechanical behaviours of elastomer fibres in the future.
\end{abstract}

Keywords: fibre; mechanical response; spinning; thermoplastic elastomer 


\section{Introduction}

Thermoplastic polyurethane elastomer is a biphasic polymer possessing both thermoplastic properties and elastomeric behaviours [1]. Owing to this thermoplastic property, polyurethane can be processed into articles with various shapes and structures while maintaining the elastomeric behaviours for many useful applications. Among all these shapes and structures, polyurethane fibres with high aspect ratio are gaining more and more interest and attention in many applications. As a matter of fact. polyurethane fibrous membranes are found to be suitable for water filtration [2, 3] and biomedical applications [4-6] due to the high porosity and surface area to volume ratio. Other applications of polyurethane fibres include energy storage [7], polymer electrolyte [8,9], protective clothing [10] and shape memory polymer [11].

The mechanical properties of polyurethane are widely studied since different forms or structures of polyurethane may exhibit different mechanical properties. For instance, polyurethane foams, films, and fibres are found to have dissimilar mechanical properties due to different microstructures [12-14]. While there are many studies on the mechanical behaviour of polyurethane in the literature, the focus is usually on polyurethane foams for their crashworthiness property [15-18] and mainly in the form of non-woven fibrous membranes [1921]. Moreover, only simple mechanical tests are usually conducted to evaluate the elastic properties, such as elastic modulus and ultimate tensile strength of the fibres. In the case of highly aligned polyurethane fibres, fewer studies are found due to the complexity of their fabrication as compared to non-woven fibrous membranes [22, 23].

As reported in many studies, non-woven polyurethane fibrous membranes can be fabricated through electrospinning [24-29]. However, the chaotic motion of the electrospinning polymer jet 
hinders the controlled deposition of the fibres on the collector and thus preventing the alignment of the fibres on the collector $[30,31]$. In order to fabricate highly aligned fibres, the conventional electrospinning set up needs to be modified. High speed rotating collectors [32] and parallel electrodes [33] are two common methods to fabricate highly aligned fibres in electrospinning. However, highly aligned fibres can only be fabricated in between the narrow gap of parallel electrodes with distance only about a few centimetres. These samples are often too small to handle for mechanical testing in conventional universal tensile machines. Similarly, a bundle of highly aligned fibres with $3 \mathrm{~cm}$ length fabricated using electrospinning over two fixed points [34] is also not suitable for mechanical testing in conventional universal tensile machines. Some researchers have also come out with special modifications to the electrospinning technique with good result in aligning the fibres [35-37]. Nevertheless, no study on the mechanical behaviour of their samples was conducted. Although increasing the rotational speed of the rotating collector in electrospinning generally increases the alignment of the fibres, the optimum speed is frequently affected by polymer types and other processing parameters. Thus, tedious parameters optimization is often needed to fabricate highly aligned fibres [38-41].

To overcome the electrospinning limitations, a simple dry spinning technique will be used to fabricate highly aligned polyurethane fibres in this study. Indeed, dry spinning would not have chaotic polymer jet path like electrospinning. The fibres drawn from dry spinning would follow a straight path to reach the rotating collector and winded on the rotating collector as long fibres in a bundle. To promote further polymeric chains alignment and fibre stretch, a relatively weak voltage is applied between the collector and the polymer solution reservoir [42]. Both fibre stretching and polymeric chains alignment along stretching direction would enhance the mechanical strength of the fibres. 
The mechanical properties of fibrous membranes are often dictated by their extrinsic surface morphology such as fibres alignment, beads, and fusion between the fibres. Indeed, during stretching, randomly orientated fibres are found to align in the direction of tensile force by sliding against each other and unfolding from the entanglement [19, 43-47]. This fibre realignment due to stretching would modify the membrane properties [43]. Beaded fibres are found to have lower mechanical strength as compared to fibres with no beads [48] whereas fibres fusion improve fibres load bearing capacity $[19,46]$.

In addition to the above aspects, the characteristics of fibres are strongly affected by their diameter. In order to study the effect of diameter on the mechanical behaviour, a single fibre has to be isolated and sophisticated mechanical testing equipment is needed. The isolation of the microfibres or nanofibers is a daunting task and thus, only simple mechanical testing can be conducted even with the use of atomic force microscope [49-51].

In this study, the macroscopic mechanical behaviour of thermoplastic polyurethane microfibres under complex loading conditions are addressed. To this end, highly aligned thermoplastic polyurethane fibres are fabricated using a simple dry spinning technique assisted by a weak electrical field. Since the resulting fibres will be loaded along their axis during the mechanical tests, no fibre re-orientation is expected. Three loading sequences are considered: monotonic tensile loading, cyclic loading with increasing maximum strain and stress relaxation. Moreover, two different strain rates are investigated: $0.001 \mathrm{~s}^{-1}$ and $0.1 \mathrm{~s}^{-1}$. As can be seen in the following, the determination of the stress-strain curve is challenging due to peculiar characteristics of microfibres produced by dry spinning technique. It is to note that attention is given to the inelastic responses exhibited by the fibres including stress-softening, hysteresis, residual 
deformation and time-dependent responses in the view of providing a basic understanding on the modelling of the mechanical behaviours of elastomer fibres in the future.

\section{Experimental section}

\subsection{Materials}

MDI-polyester/polyether polyurethane (a thermoplastic elastomer) pellets with CAS number of 68084-39-9 were used as the base material to fabricate the polymeric fibres. These thermoplastic elastomer pellets have the density of $1.18 \mathrm{~g} / \mathrm{ml}$ and glass transition temperature of $-40{ }^{\circ} \mathrm{C}$ as stated in the specification sheet. The chemical structure of the polyurethane is shown in the Figure 1. Soft domains of the polyurethane are comprised of the polyester [52] and polyether [53] groups, whereas the hard domains are comprised of the methylene diphenyl diisocyanate (MDI) [52] groups.

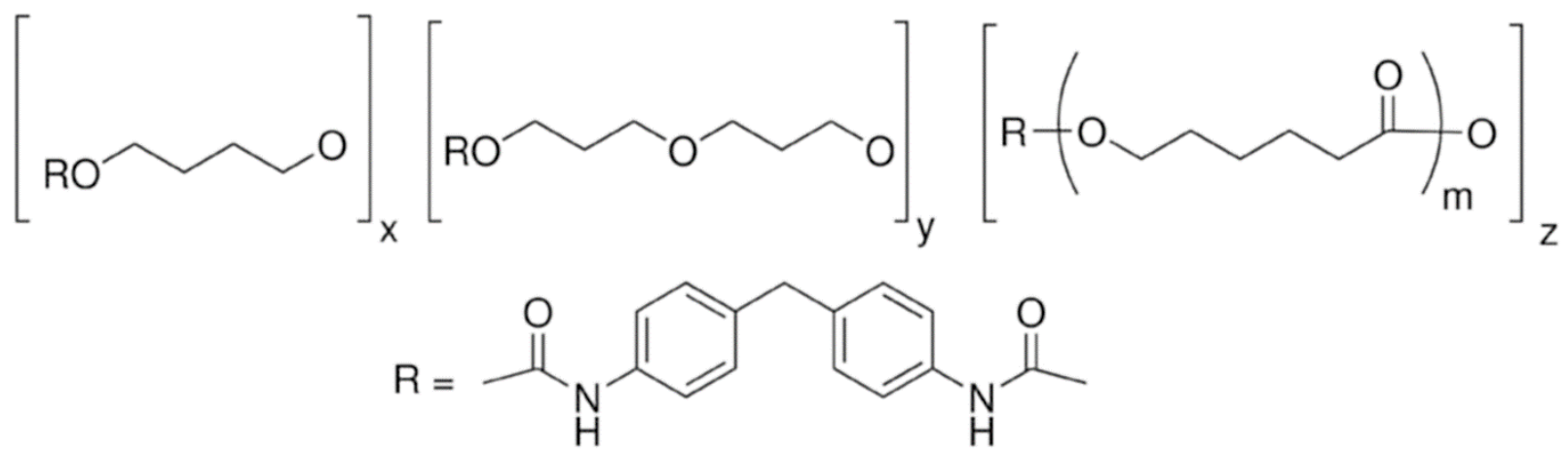

Figure 1. Chemical structure of MDI-polyester/polyether polyurethane obtained from the specification sheet 
N,N-Dimethylformamide (DMF) and Tetrahydrofuran (THF) with purity more than $99 \%$ were used as solvents to dissolve the MDI-polyester/polyether polyurethane pellets. The base material and all chemicals were purchased from Sigma Aldrich. They were used as received without further processing.

\subsection{Fabrication of highly aligned fibres}

The $15 \mathrm{wt} \%$ polyurethane solution was prepared by dissolving the polyurethane pellets in a mixture of DMF and THF in the ratio of 1:1 at ambient condition. Polyurethane fibres fabricated from this solvent ratio is found to have the best morphology and mechanical properties [54]. Then, the solution was filled into a syringe with a needle gauge size of 27 G. A syringe pump was used to control the solution feed rate at $0.05 \mathrm{ml} / \mathrm{hr}$. Fibres were subsequently towed to a rotating drum at a distance of $15 \mathrm{~cm}$ to initiate the dry spinning process in the ambient condition. This $8 \mathrm{~cm}$-diameter drum rotated at the speed of around $100 \mathrm{rpm}$. Finally, a positive voltage supply of $1 \mathrm{kV}$ was applied between the needle and the rotating drum to further elongate the fibres. An illustration of the fabrication is shown in Figure 2. It is to note that despite of the effort in maintaining the consistency of the fabrication process, for a given fabrication duration, it was difficult to obtain the same amount of fibres in a sample between batches of fabrication. Indeed, for the same fabrication condition, the resulting masses of the fibres are not necessarily the same. Consequently, as will be elaborated further in the next section, careful consideration should be given when treating the data obtained from mechanical tests. 


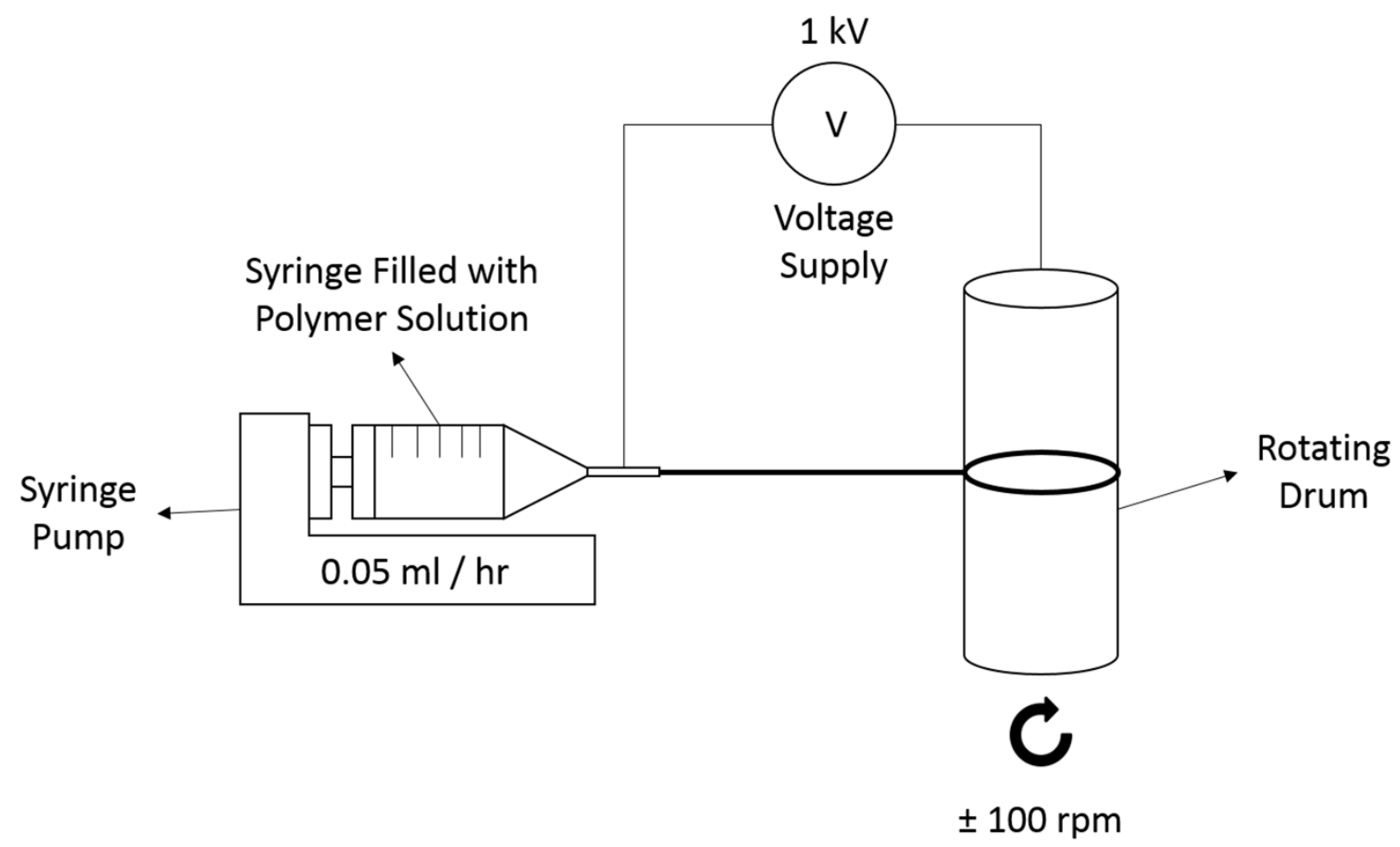

Figure 2. Illustration of the fibres fabrication technique

\subsection{Surface morphology characterisation}

The fibres surface morphology was observed under the Phenom ProX desktop scanning electron microscope $($ SEM) with $1000 \times$ magnification and $5000 \times$ magnification. The micrographs with the magnification of $1000 \times$ were used for fibres orientation analysis. Similarly to the work of Wong et al. [43], two assumptions were made: the fibre orientation was in plane and the orientation at the top layer was considered to represent the average fibre orientation of the whole sample. The diameter of 100 fibres from the $5000 \times$ magnification micrographs were measured to get the mean value and the standard error. Both the orientation analysis and diameter measurement were done using the ImageJ $1.48 \mathrm{v}$ software. OrientationJ Distribution processing method in OrientationJ plugin was used for orientation analysis, whereas the diameter measurement was evaluated using the measuring tools in the software. 


\subsection{Estimation of initial sample cross-sectional area}

In view of analysing the mechanical test results, information on tensile specimen cross-sectional area is needed. Due to the irregular shape and small size of fibres, obtaining a precise sample cross-sectional area is a daunting task. Furthermore, since thermoplastic polyurethane elastomeric fibres are soft materials, the cross-sectional shape may be easily distorted under slight excessive force which might occur during the measurement. To overcome this difficulty, indirect measurement was conducted. First, the fabricated bundles of fibres were cut into $6 \mathrm{~cm}$ length, with $4 \mathrm{~cm}$ as the gauge length and $1 \mathrm{~cm}$ each at both ends of the sample to be clamped during the tensile test. Then, the mass of the sample was measured before clamping it to the uniaxial tensile machine. Additional precaution was taken by casting water soluble poly(vinyl alcohol) at the clamping region of the sample to prevent premature failure and slipping of the sample through the grip of the tensile machine during the test. After properly clamping the sample as shown in Figure 3(a), dino-lite digital microscope was used to capture perpendicularly the image at the middle of the gauge length of the samples. For each sample, an image was taken from every $30^{\circ}$ angle of viewing, starting from $0^{\circ}$ to $360^{\circ}$. Thus, a total of 12 images were obtained from each sample. An example of image taking at several angles of $0^{\circ}, 30^{\circ}, 90^{\circ}$ and $120^{\circ}$ is illustrated in Figure 3(b). By assuming circular cross-sectional area, diameters measurement was done in these 12 images. The equivalent diameter, $D$ for the irregular crosssectional area was calculated to compensate for the lack of circularity of the sample using

equation $D=\sqrt{D_{1} D_{2}}$, where $D_{1}$ and $D_{2}$ are two perpendicular diameters as previously measured [55]. A total of 12 equivalent circular diameters were measured for each sample and the average value was computed. 


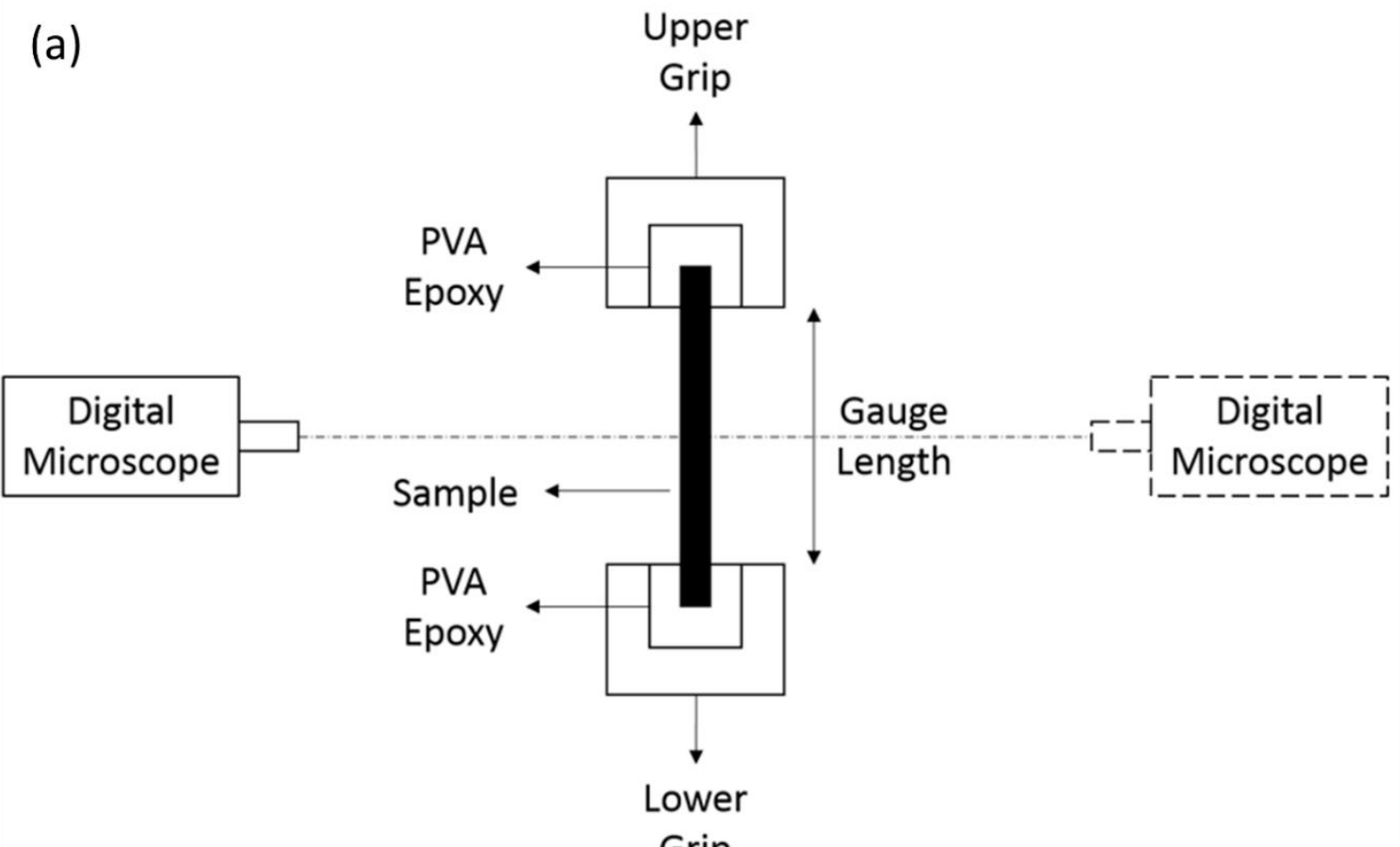

(b)

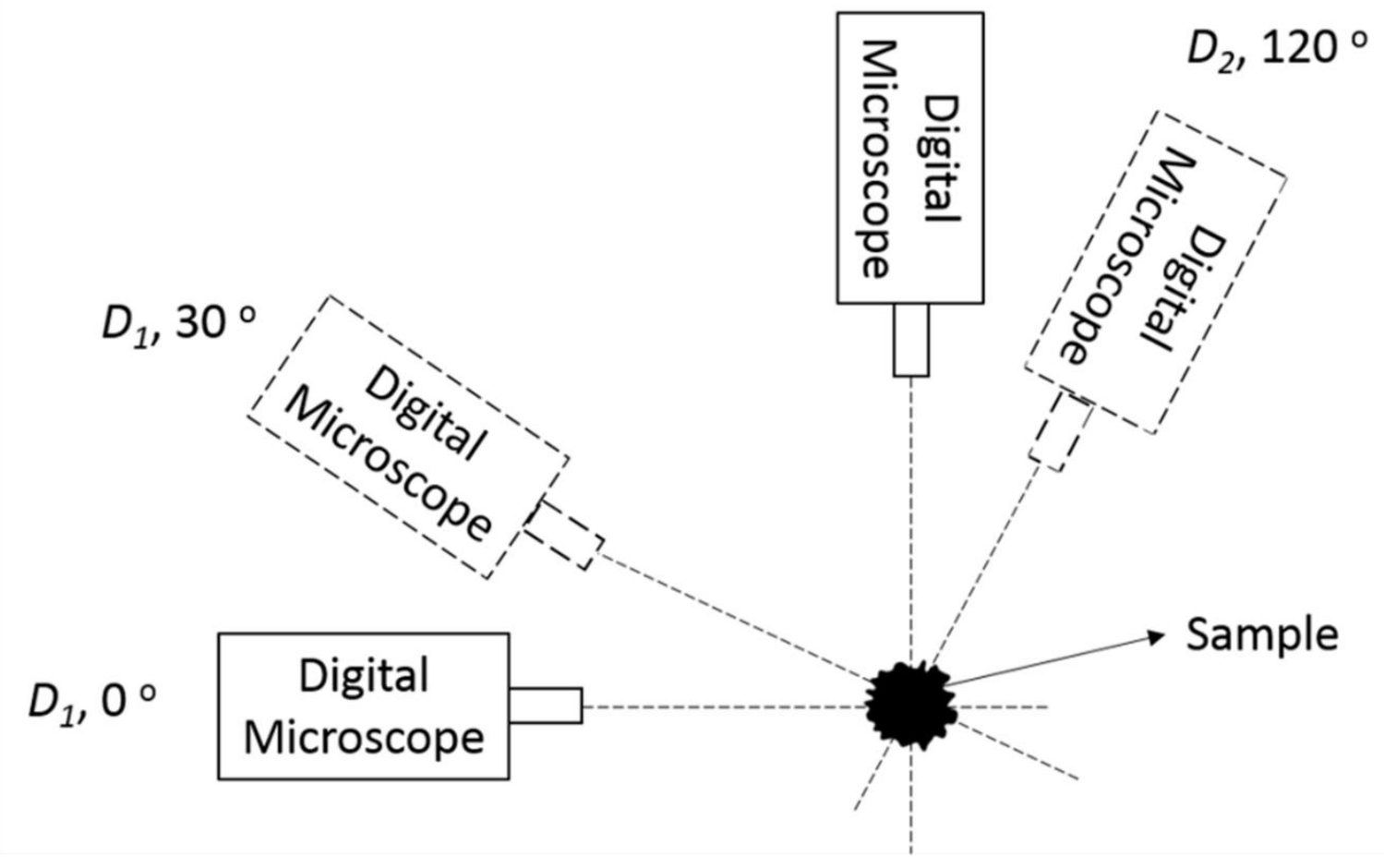

Figure 3. Illustration of (a) front view of the sample gripped at the tensile machine and (b) top view of the sample 
As highlighted in Section 2.2, the same fibre fabrication condition did not necessarily lead to the same number of fibres, i.e. cross-sectional area may differs from one sample to another. Thus, the indirect measurement method described in the previous paragraph must be repeated for all samples of mechanical test. For the sake of simplicity, the indirect measurements of initial crosssectional area were only conducted on 8 representative samples used for monotonic tensile test. The ratio between initial cross-sectional area and mass was subsequently calculated for each sample and the corresponding average over 8 samples was computed. It was found that the average cross-sectional area to mass ratio, denoted $\alpha$, was $93.4 \mathrm{~mm}^{2} \mathrm{~g}^{-1}$. Finally, since all the samples are produced from the same precursor, by assuming that all samples have the same density, the initial cross-sectional area, $A$ of any other tensile sample can be easily estimated by multiplying the above average ratio with the sample mass, $m$, i.e. $A=\alpha m$.

\subsection{Mechanical testing}

The mechanical tests were conducted using Shimadzu AGS-X Series Universal Tensile Testing Machine equipped with a $5 \mathrm{kN}$ load cell. Three mechanical tests were conducted: uniaxial monotonic tensile test, cyclic tensile test with increasing maximum strain and relaxation tensile test. They were performed at two different strain rates: $0.1 \mathrm{~s}^{-1}$ and $0.001 \mathrm{~s}^{-1}$. The loading profiles for the uniaxial cyclic tensile test and relaxation tensile test are illustrated in Figure 4. During the cyclic test, the unloading was set to stop when the force was $0 \mathrm{~N}$ instead of $0 \%$ strain before starting the next cycle as shown in Figure 4(a) in order to prevent the sample from buckling. In the case of relaxation tensile test, the samples were held at strains of $20 \%$ and $40 \%$ as shown in Figure 4(b). Please note that only uniaxial monotonic tensile test at $0.001 \mathrm{~s}^{-1}$ were conducted for 8 times due to the reason mentioned in the previous section. All other tests were conducted twice. 


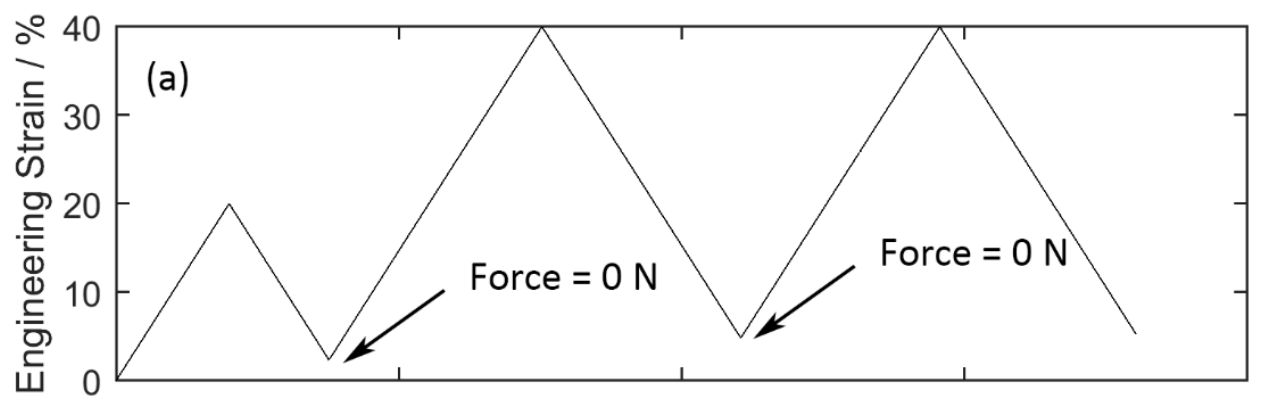

Time

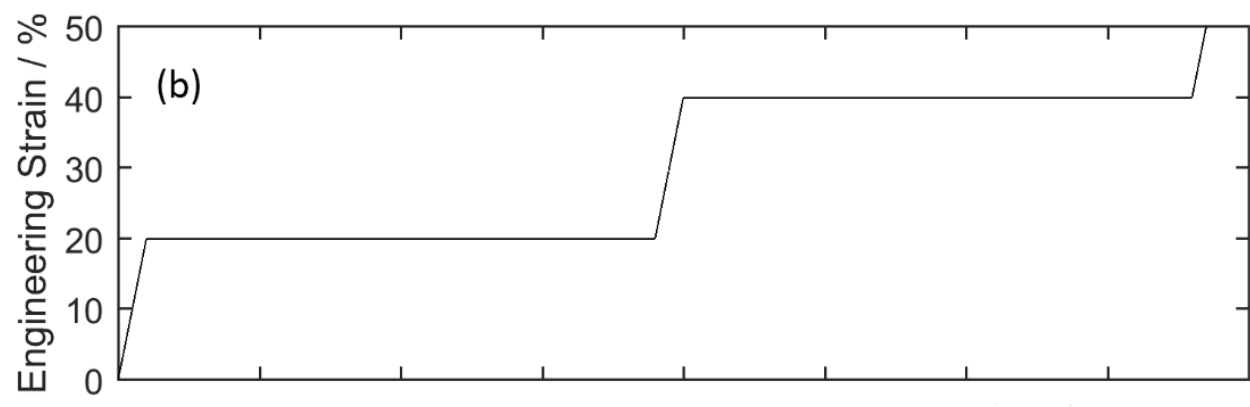

Time

Figure 4. Loading profile for (a) cyclic tensile test and (b) relaxation tensile test

\section{Results and discussion}

\subsection{Surface morphology characterisation}

The bundles of fibres with length of $21.4 \mathrm{~cm}$ fabricated from the dry spinning technique assisted by electrical field were observed under SEM. The micrographs of the fibres are shown in Figure 5. 

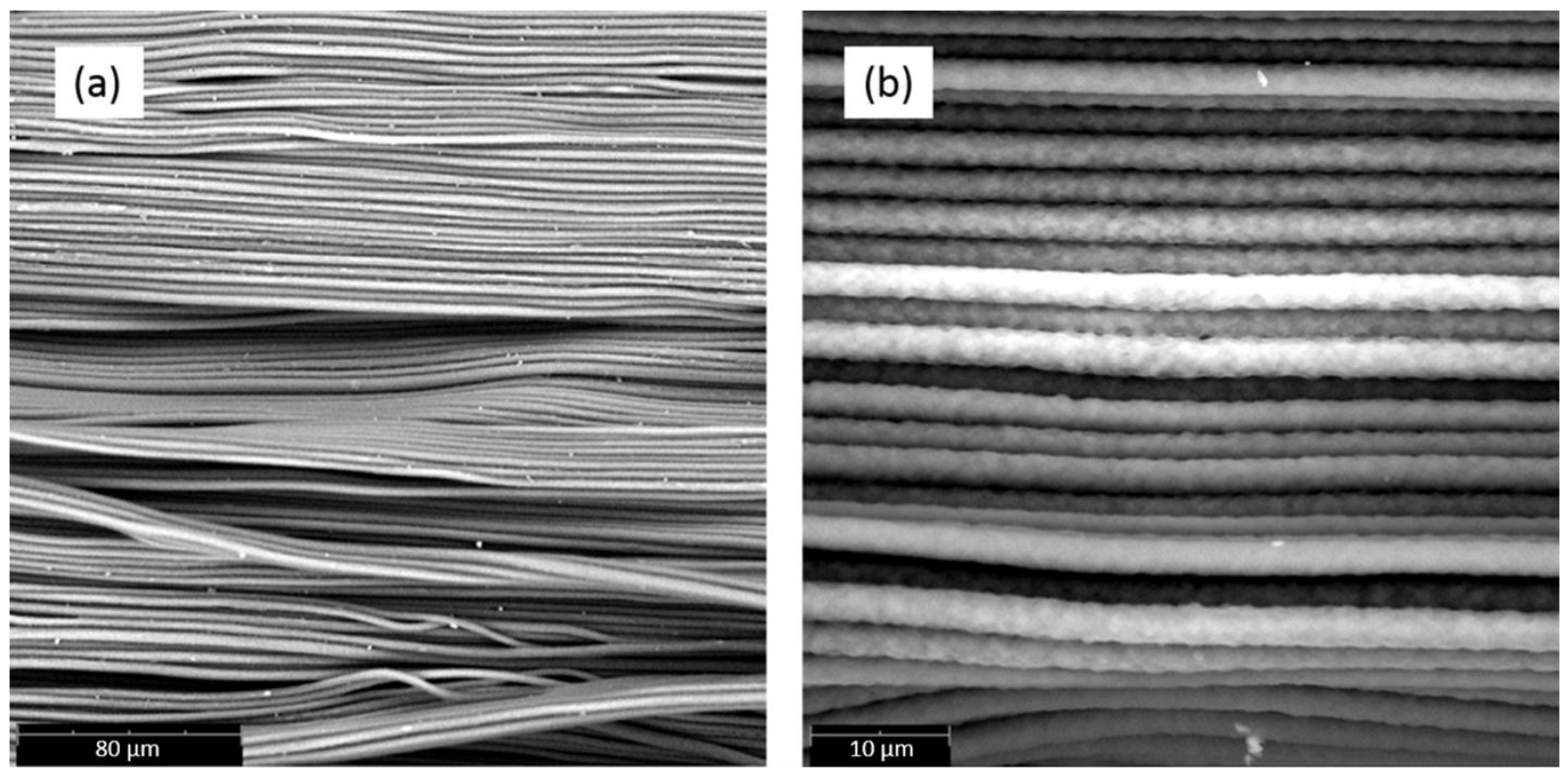

Figure 5. SEM micrograph of polyurethane fibres under the magnification of (a) $1000 \times$ and (b) $5000 \times$

Based on Figure 5, the fibres are found to be highly aligned and closely packed with no beads. The fibre diameter and orientation distribution are shown in Figure 6. The mean fibre diameter is $2.80 \pm 0.06 \mu \mathrm{m}$ with the alignment of the fibre axis concentrated in the angle of $-3^{\circ}$ as indicated in the orientation distribution curve in Figure 6(b). A sharp peak is observed for highly aligned fibres, unlike the broad peak or no peak found in previous studies on non-woven fibres [43, 47]. 

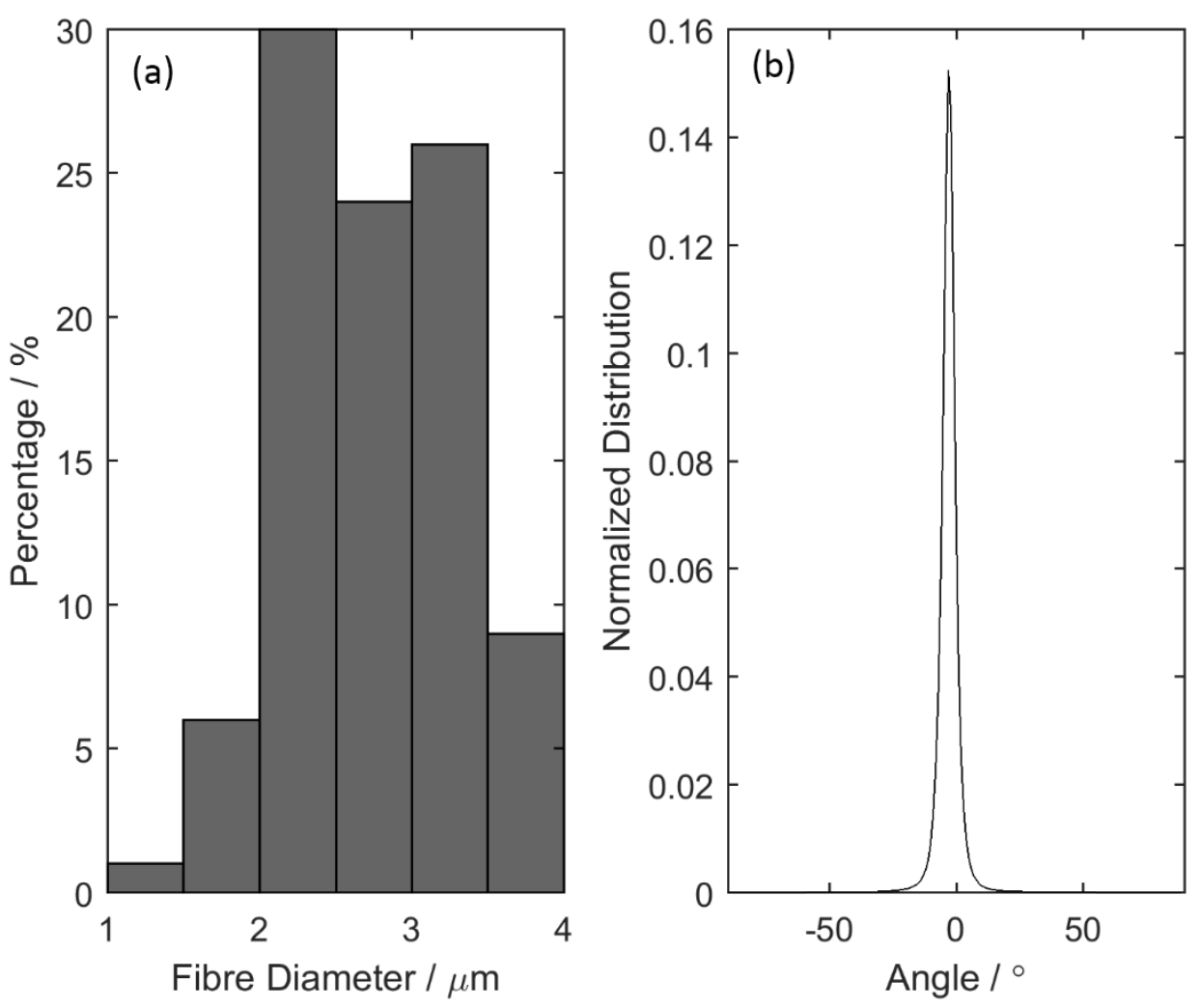

Figure 6. (a) Diameter distribution and (b) orientation distribution of polyurethane fibres

\subsection{Mechanical testing}

\subsubsection{Uniaxial monotonic tensile test}

Monotonic tensile test with the strain rate of $0.001 \mathrm{~s}^{-1}$ was carried out on 8 samples fabricated from different batches of production. The force-displacement curves are presented in Figure 7(a) in order to study the consistency among different batches of samples. It is observed that the 8 curves do not coincide with each other which suggests that each tensile sample does not contain the same number of fibres, i.e. the mass varies from one sample to another. Nevertheless, their diameters are found to be similar. Consequently, samples with different masses will have 
different amount of fibres and sustain different magnitude of load although undergoing the same condition of mechanical test.

Using the estimation of sample initial cross-sectional area as detailed in Section 2.4, the engineering stress-strain curves of 8 samples are plotted in Figure 7(b), showing closer agreement between them. In the following discussion, for the sake of simplicity, the terms "stress" and "strain" refer to "engineering stress" and "engineering strain" respectively.
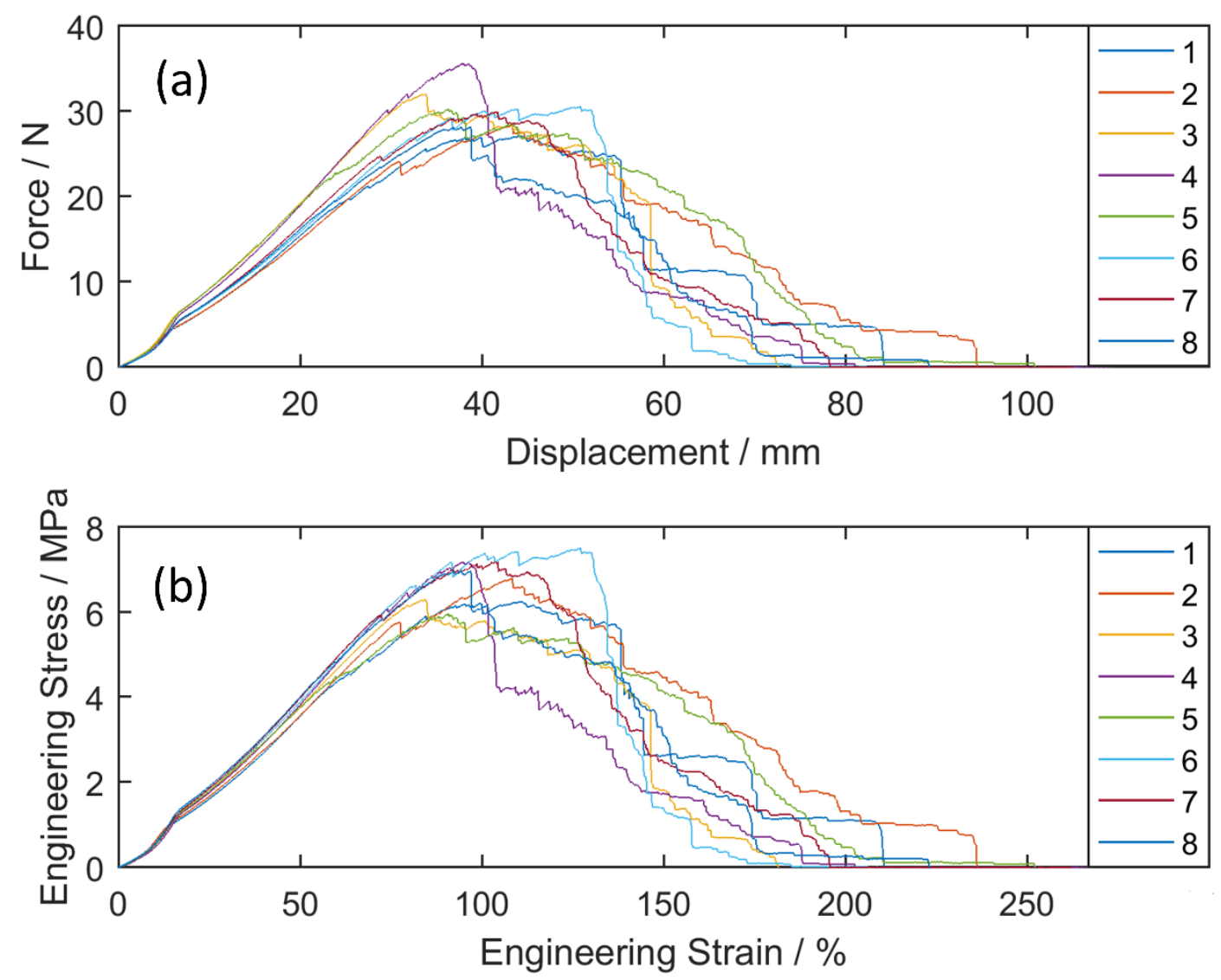

Figure 7. (a) Force versus displacement curves of eight samples under monotonic tensile tests;

(b) Engineering stress-strain curves of monotonic tensile tests 
According to Figure 7, the samples fail or fracture gradually rather than abruptly after reaching the ultimate tensile strength. An illustration of the gradual fracture of the samples is shown in Figure 8 , transitioning from a to d. Initially, the width of the sample continuously decreases, changing from a to $b$. After reaching the ultimate tensile strength, the sample starts to fracture bit by bit as shown by $\mathrm{c}$ and $\mathrm{d}$. This may be due to the fact that all the fibres in a bundle do not have the same diameter but instead a distribution of diameters as indicated in Figure 6(a). Thus, the fibres fail according to the size of diameter as small diameter fibres can withstand lower load than large diameter fibres. This gradual fibre failure is in line with the work of Wei et al. [56]. The ultimate tensile strength, defined as the highest stress level achieved during the monotonic tensile test, is found to be $6.77 \pm 0.17 \mathrm{MPa}$ at the strain rate of $0.001 \mathrm{~s}^{-1}$. 


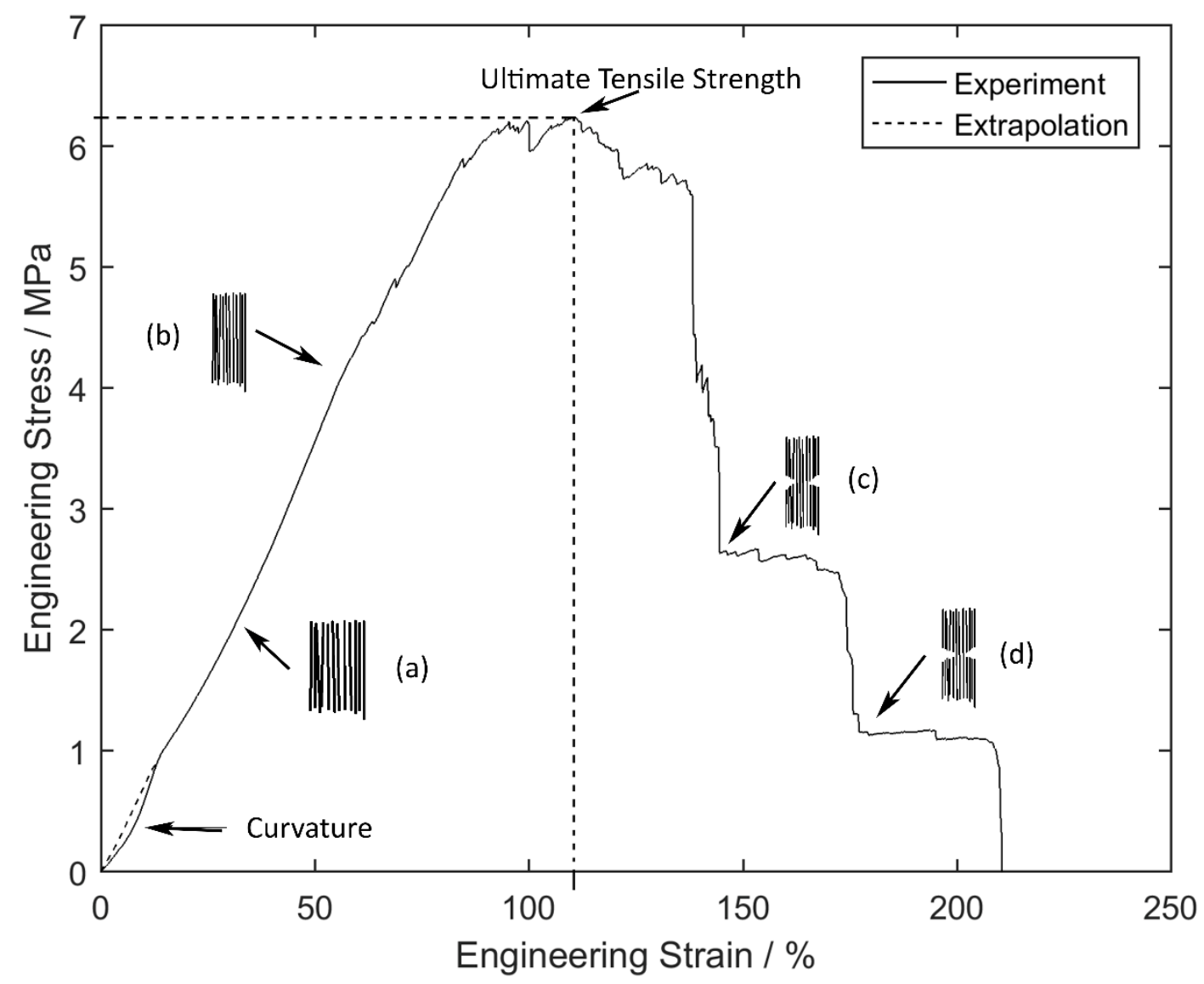

Figure 8. Representative engineering stress-strain curve of monotonic tensile tests with extrapolation (in dashed line) at the beginning of the engineering stress-strain curve under monotonic tensile test

A small curvature at the beginning of every stress-strain curves before the strain of $20 \%$ can be observed and labelled in Figure 8. This non-linear phenomenon before the linear stress-strain behaviour of the samples is similar to the crimped collagen fibres in tendons and ligaments [57]. Nevertheless, the nature of this non-linearity or toe region of these crimped collagen fibres is different from the polyurethane fibres in the present study. The toe region of the collagen fibres is originated from the straightening of the fibres [58, 59]. By referring to Figure 5, the fabricated polyurethane fibres have straight structure instead of crimp one. In fact, due to the nature of dry 
spinning process, the fibres are subjected to a pre-stretch during the processing, marked by the shrinkage of the fibres during the removal from the collector. The corresponding pre-stretch yields to a stress-softening in the materials as can be observed during the tensile test. The stresssoftening is commonly found in an elastomer [60,61]. Extrapolation is done as illustrated in Figure 8 (represented by a dashed line in the beginning of stress-strain curve) to compensate for the stress-softening effect. Ignoring the corresponding stress-softening due to pre-stretch during fibre fabrication, the initial modulus is found to be $7.76 \pm 0.15 \mathrm{MPa}$.

The stress-strain curve of polyurethane fibres in Figure 8 does not show a sigmoidal shape like a typical elastomer. It is known that sigmoidal shape stress-strain curve of bulk polyurethane will change to nearly linear trend once processed into fibres [14].

Monotonic tensile test with higher strain rate of $0.1 \mathrm{~s}^{-1}$ were also conducted. Figure 9 shows the representative stress-strain curves taken from two samples for strain rates of $0.001 \mathrm{~s}^{-1}$ and $0.1 \mathrm{~s}^{-1}$ respectively. It is found that the sample tested with the higher strain rate has higher initial modulus and ultimate tensile strength of $8.15 \pm 0.21 \mathrm{MPa}$ and $9.32 \pm 0.85 \mathrm{MPa}$ respectively. This finding is similar to a study on a bulk polyurethane by Fan et al. in which the transition of rubbery to glassy state occurs as the strain rate increases [62]. Another study by Yi et al. shows that polyurethane will mechanically recognise higher glass transition temperature under higher strain rate making it stiffer and stronger [63]. 


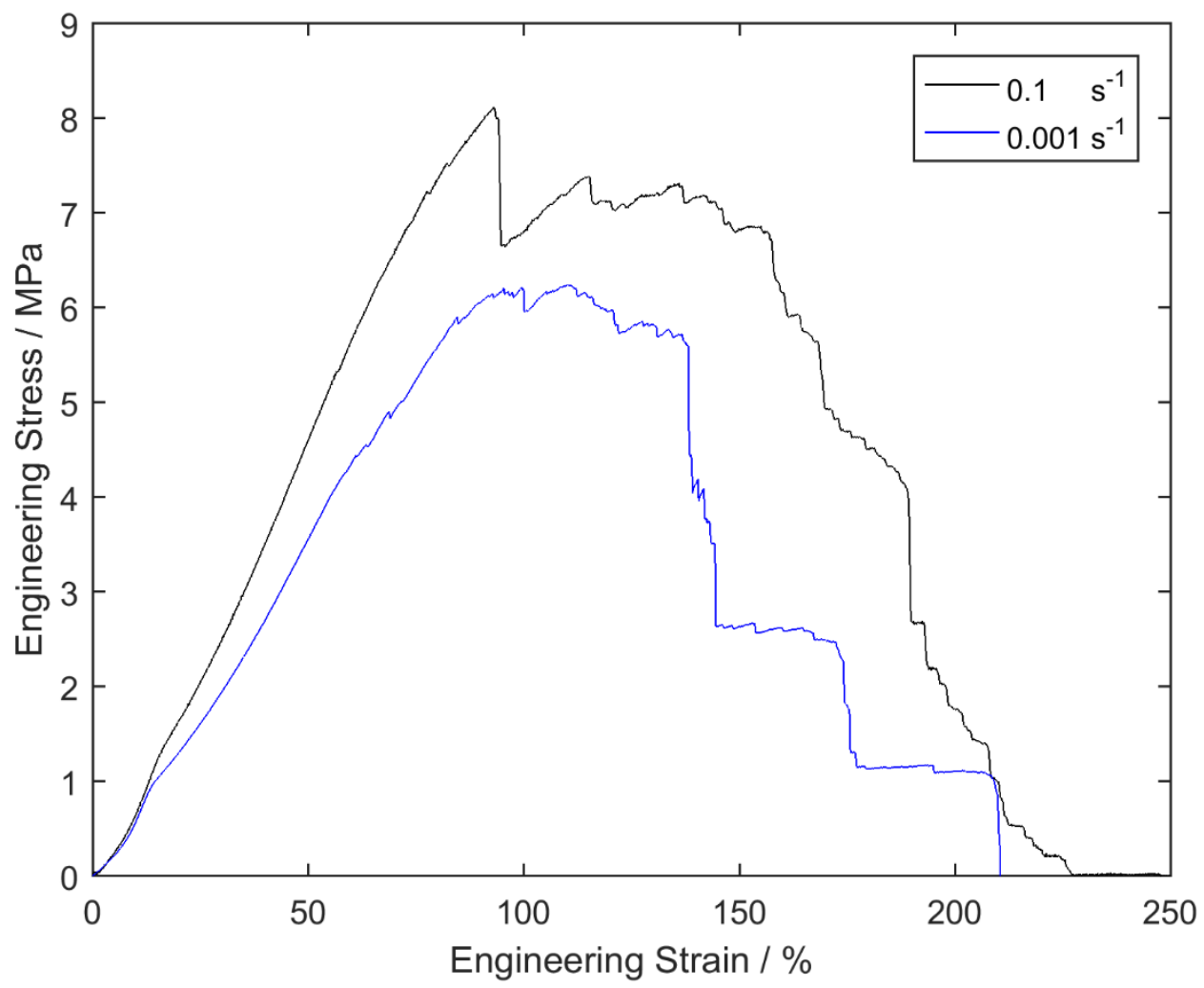

Figure 9. Representative engineering stress-strain curves of tensile samples undergoing monotonic tensile at two different strain rates

The mechanical strength of polyurethane is generally attributed to the hard domains of polyurethane [60]. In our study, the hard domains correspond to the MDI groups. According to Buckley et al. [64], the tensile moduli of bulk MDI based polyurethanes range from $39.2 \mathrm{MPa}$ to 85.7 MPa at the strain rate of $0.03 \mathrm{~s}^{-1}$, much higher than the initial moduli of the MDI based polyurethane fibres fabricated in this study, which are 7.76 $\pm 0.15 \mathrm{MPa}$ and $8.15 \pm 0.21 \mathrm{MPa}$ at $0.001 \mathrm{~s}^{-1}$ and $0.1 \mathrm{~s}^{-1}$ respectively. This may be due to the overestimation of the effective cross sectional area where the porosity within the fibres and the voids between the fibres in the bundles were considered in the measurements of this study. 


\subsubsection{Uniaxial cyclic tensile test}

Figure 10 shows the representative stress-strain curves of materials under cyclic tensile loading at $0.1 \mathrm{~s}^{-1}$ and $0.001 \mathrm{~s}^{-1}$ strain rates. For each curve, a hypothetical $1^{\text {st }}$ cycle curve is extrapolated to remove the effect of softening due to pre-stretch during processing. Similarly to the monotonic tensile test, cyclic tensile tests with higher strain rate yield to stiffer and stronger material responses than those at lower strain rate. Obvious inelastic responses, such as stress-softening, hysteresis, and residual deformation are observed. Another inelastic mechanical behaviour can be observed at the cycles to maximum strain of $40 \%$. For the same maximum strain, lower maximum stress level is observed at the $2^{\text {nd }}$ cycle than the $1^{\text {st }}$ cycle. This phenomenon is named as permanent stress set [65]. In the literature, these unique mechanical behaviours of polyurethane are attributed to the microstructural changes during the cyclic test. Indeed, the restructuring of the hard domains is found to impart the inelastic mechanical properties to polyurethane in cyclic mechanical loading [66]. 


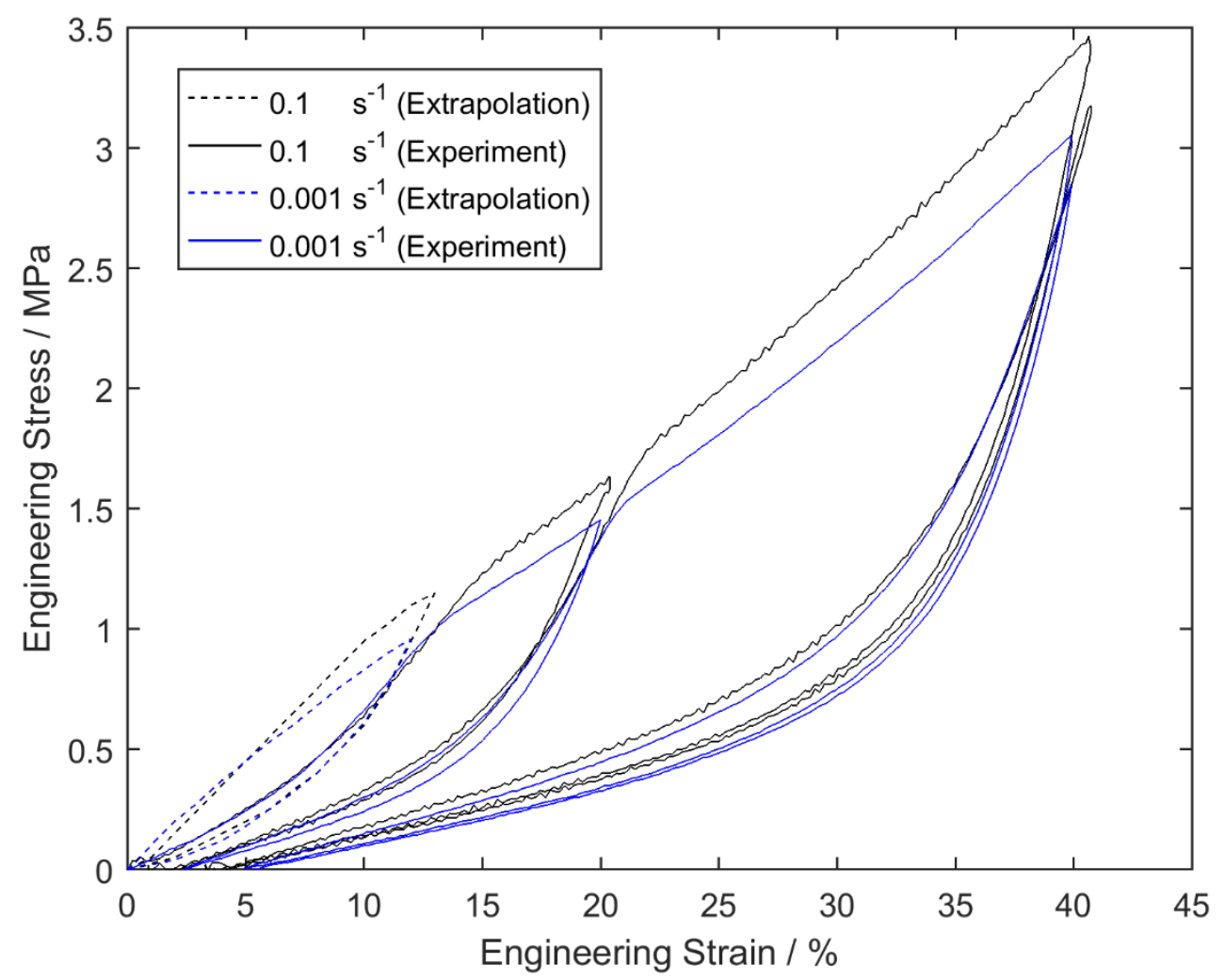

Figure 10. Representative engineering stress-strain curves of tensile samples undergoing cyclic tensile test at two different strain rates

\subsubsection{Residual deformation}

During unloading, polyurethane fibres do not completely return to $0 \%$ strain. Instead, they retain certain amount of residual strain after unloading the material to $0 \mathrm{~N}$ force during uniaxial cyclic tensile tests. These residual strains or deformations are tabulated in Table 1. The extrapolated first cycle is assumed to have no residual strain since no experimental data is available as the pre-stretch occurred during the fabrication process before the mechanical test. 
Table 1. Residual deformation of the samples at different strain rate and maximum strain Strain Rate / $\mathrm{s}^{-1}$ Maximum Engineering Strain / \% Residual Deformation / \%

\begin{tabular}{lcc}
\hline & 20 & $1.05 \pm 0.12$ \\
& 40 & $3.45 \pm 0.12$ \\
0.001 & 20 & $2.61 \pm 0.14$ \\
& 40 & $5.29 \pm 0.27$ \\
\hline
\end{tabular}

The results in Table 1 suggest that the residual deformation depends on maximum strain and strain-rate. The residual strain increases with the maximum strain and decreases as the strain rate increases. Nonetheless, the residual strain remains almost constant if the loading does not exceed the previous cycle's maximum strain.

\subsubsection{Hysteresis}

Hysteresis formed when the unloading path does not follow the loading path in a cyclic loading. The cycles in the cyclic test are separated individually for better illustration of hysteresis in Figure 11. Polyurethane fibres have significant hysteresis as shown in Figure 11(a)-(c). However, it is noteworthy that the hysteresis is very small if the maximum strain of the cycle does not exceed the maximum strain of the previous cycle as shown in Figure 11(d). Based on Figure 11 also, the unloading curves are found to be identical irrespective to the strain rate, consistent with the unloading behaviour found in the compressive cyclic loading of bulk polyurethane [60]. 

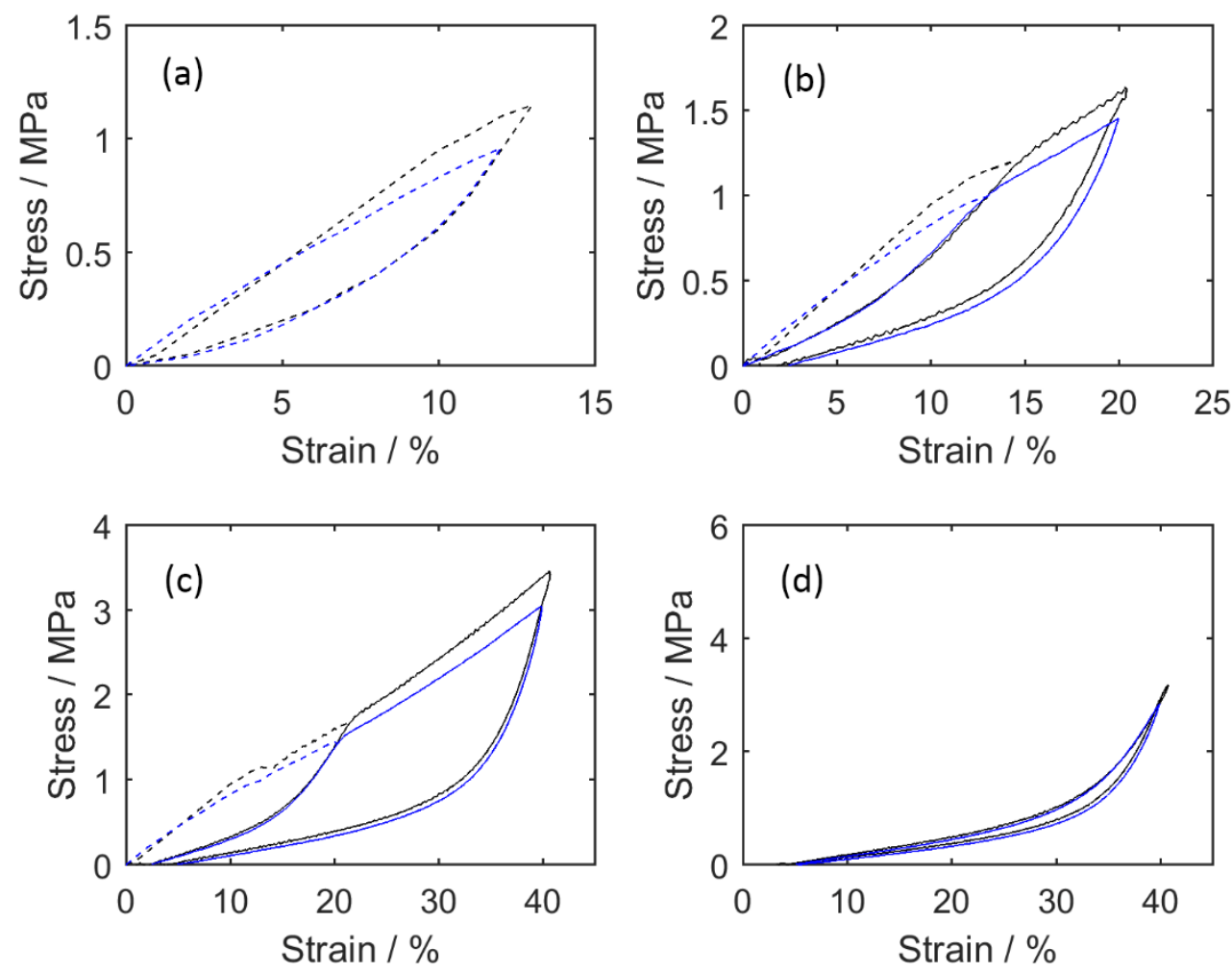

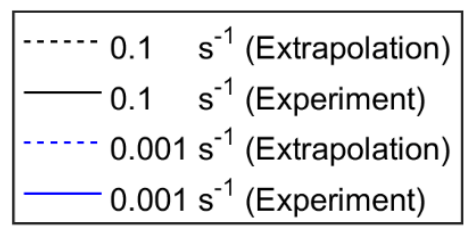

Figure 11. Hysteresis of sample under cyclic loading at: (a) hypothetical $1^{\text {st }}$ cycle due to prestretch during processing, (b) $1^{\text {st }}$ cycle of $20 \%$ maximum strain, (c) $1^{\text {st }}$ cycle of $40 \%$ maximum strain, (d) $2^{\text {nd }}$ cycle of $40 \%$ maximum strain

The hysteresis loss ratio is calculated following the work of Bergstrom and Boyce [67] and plotted against maximum strain in Figure 12. It is the ratio of stabilised hysteresis after 5 or more cycles (area of the hysteresis) and the energy supplied during loading (area under the loading curve). However, only one cycle is considered into the calculation in this study. All cycles are treated as if the stress-softening effect from prior loading is not existed as extrapolated in Figure 
11(a)-(c). Generally, the hysteresis and hysteresis lost ratio increase as the maximum strain increases. Nevertheless, the hysteresis lost ratio is higher at lower strain rate at any strain, attributed to the similar amount of hysteresis but higher energy supplied during loading. As for the $2^{\text {nd }}$ cycle with same maximum strain with the $1^{\text {st }}$ cycle, $40 \%$, the hysteresis is considerably small, having low hysteresis loss ratios of $0.221 \pm 0.007$ at $0.001 \mathrm{~s}^{-1}$ and $0.157 \pm 0.003$ at $0.1 \mathrm{~s}^{-1}$ strain rate respectively. In this study, the hysteresis property of this particular polyurethane is opposite to the typical elastomers, such as natural rubber and styrene-butadiene rubber where the hysteresis loss ratio increases with strain rate [68].

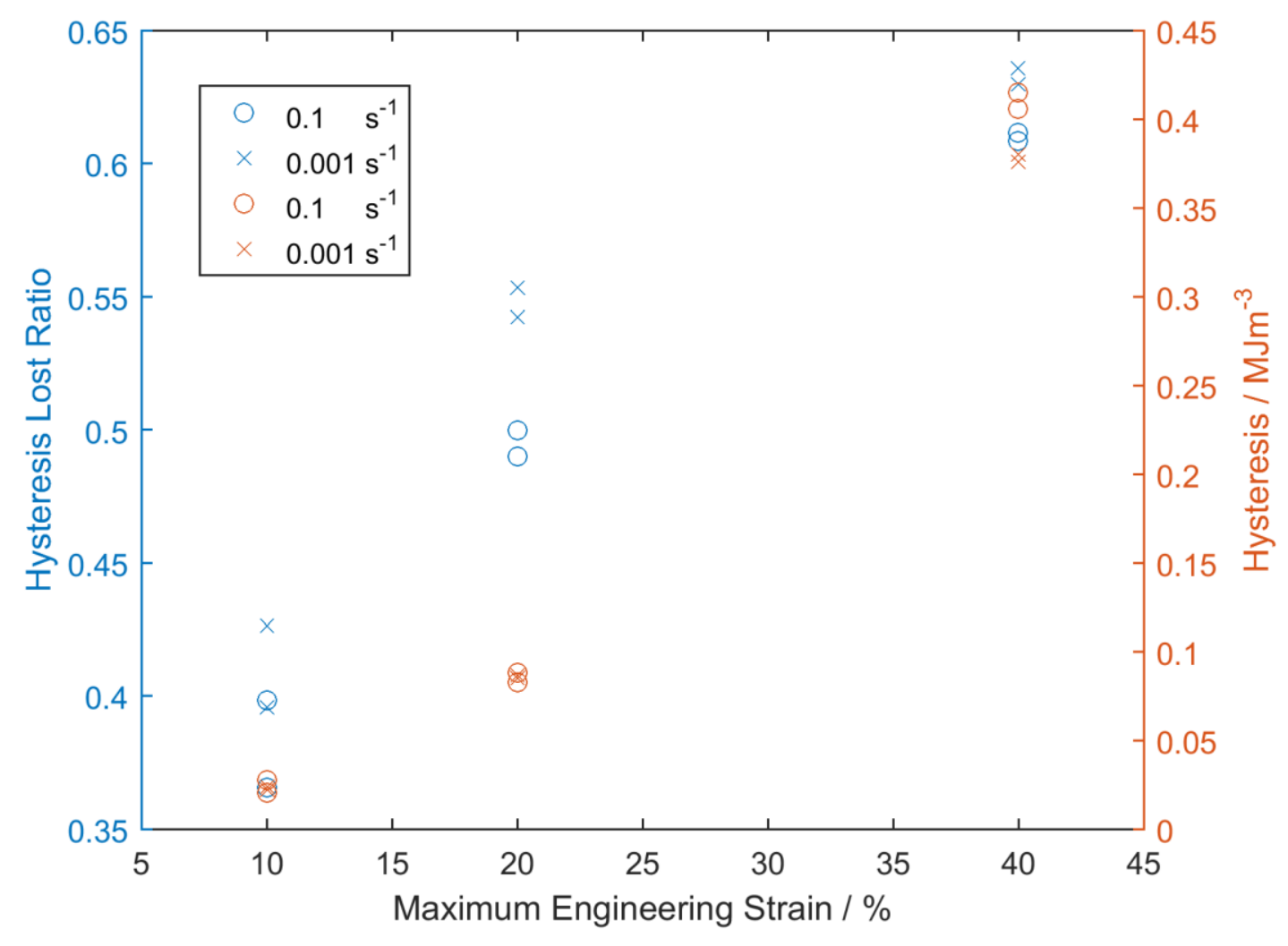

Figure 12. Hysteresis lost ratio and hysteresis against maximum engineering strain 
It is observed that almost same amount of hysteresis at the two strain rates, except for $40 \%$ strain, where the amount of hysteresis is slightly higher at $0.1 \mathrm{~s}^{-1}$ strain rate. As for the energy supplied during the loading, it is higher at higher strain rate due to the higher stiffness and strength as shown in Figure 9 and 10. Mechanical properties of the polyurethane can be altered by changing the chemical formulation and morphology, allowing greater flexibility in hysteresis and other mechanical properties. The amount and shape of hysteresis may vary even from one and another [63]. This existence of hysteresis is often related to the irreversible damage to the hard domains and weakening of the hydrogen bonds in the microstructure of thermoplastic polyurethane elastomer [66, 69].

\subsubsection{Stress-softening}

The stress softening of the polyurethane fibres is clearly noticeable after every cycle as shown in Figure 11. In order to evaluate the extent of stress-softening, only the loading curves to the same strain are considered as shown in Figure 13. The degree of stress-softening is evaluated in two ways: overall and instantaneously. Overall stress-softening is computed by finding the ratio of the difference between supplied energy during the $1^{\text {st }}$ uploading curve and the $2^{\text {nd }}$ uploading curve to the energy supplied during the $1^{\text {st }}$ uploading curve. Energy supplied is defined as the area under the uploading curve. As for the instantaneous stress-softening, it is defined as the ratio of the difference between the two stress level at the $1^{\text {st }}$ and $2^{\text {nd }}$ loading curves to the stress level at the $1^{\text {st }}$ loading curve during every strain level, adopted from the study of Chai et al. [70]. 

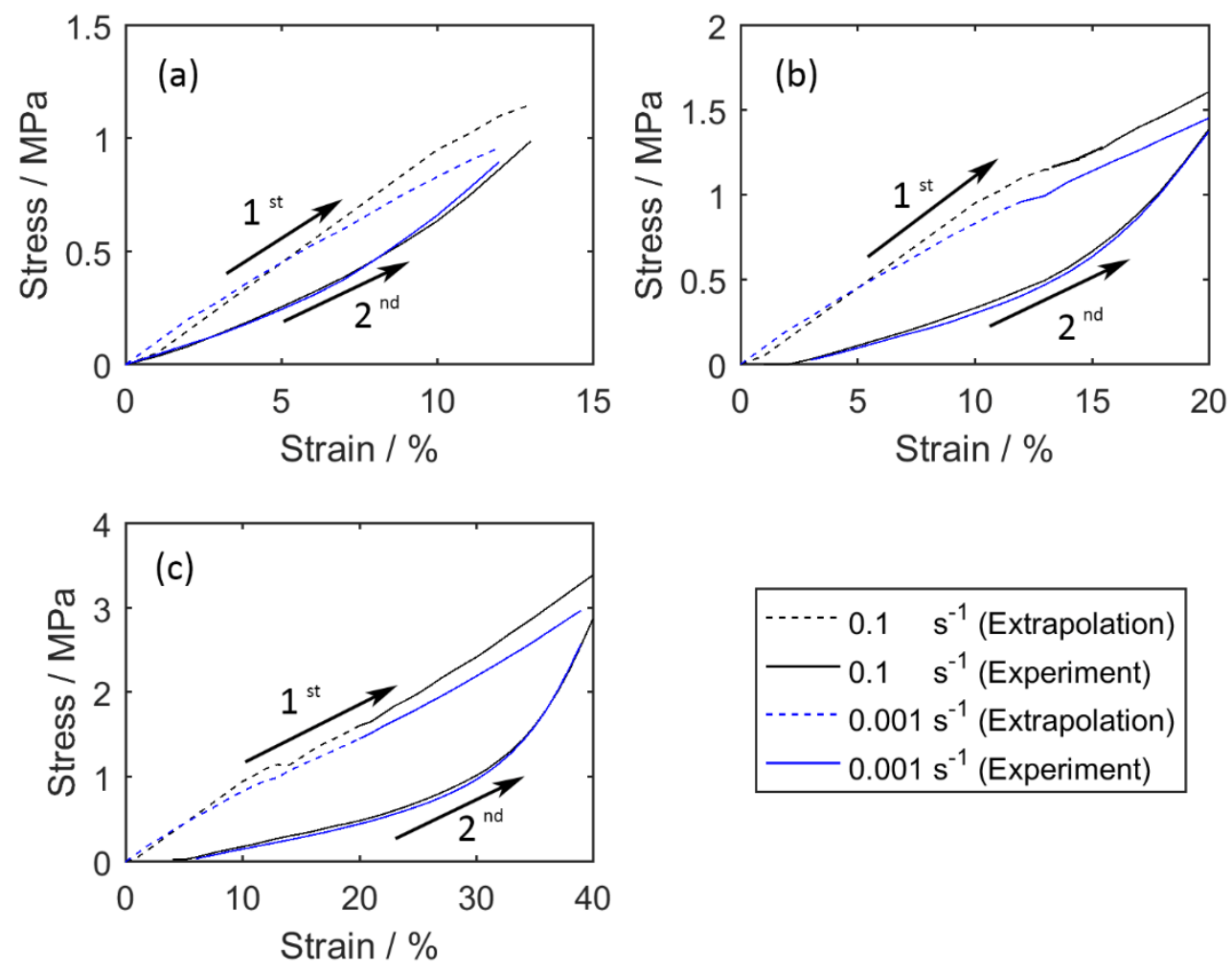

Figure 13. $1^{\text {st }}$ and $2^{\text {nd }}$ loading curves at (a) 10\% strain, (b) 20\% strain and (c) $40 \%$ strain

The overall and instantaneous stress-softening effects are shown in Figure 14. In general, the stress-softening appears to be strongly dependent on the maximum strain but nearly independent of the strain rate. Stress-softening in elastomers is often associated to the polymeric chains disentanglement, bond or cross-linking and filler rupture [35, 71-73]. Hard domains and the hydrogen bonding in thermoplastic polyurethane elastomer are analogous to the typical fillers and chemical cross-linking in elastomers respectively [74]. Thus, stress-softening and hysteresis are actually similar in nature since both phenomena in polyurethane fibres are nearly unaffected by strain rate as shown in Figure 12 and Figure 14. 

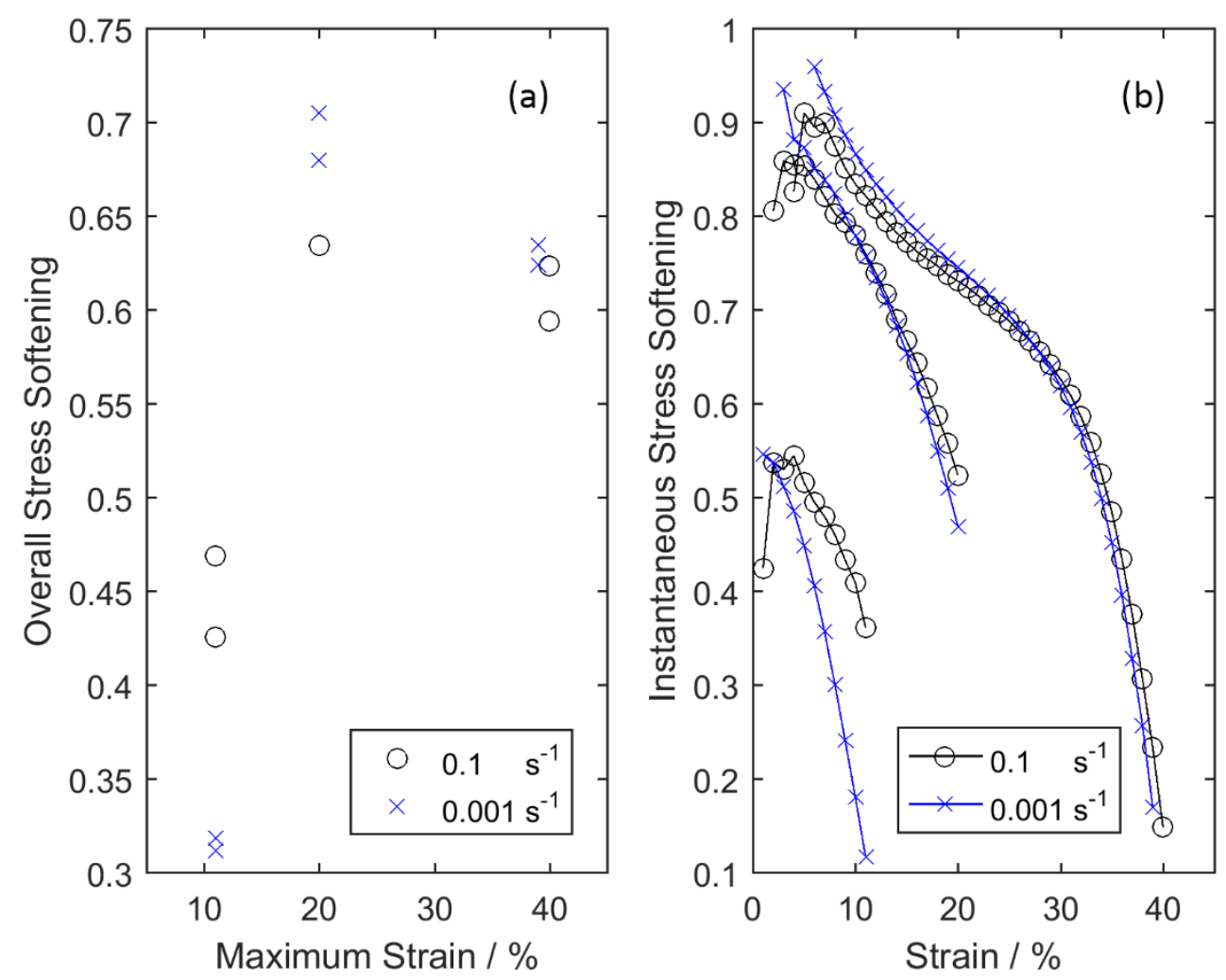

Figure 14. (a) Overall and (b) representative instantaneous stress softening at maximum strain level of $10 \%, 20 \%$ and $40 \%$ under two different strain rates

In the case of instantaneous softening, its value is initially high before decreases significantly as the strain approach its maximum independently of strain-rate or maximum strain. This suggests that most instantaneous stress-softening occurs at the beginning of the $2^{\text {nd }}$ uploading. In addition, the rate of instantaneous stress-softening appears to become lower when the maximum strain increases as shown in Figure 14(b). Very distinctive reduction in the instantaneous stresssoftening rate along to the maximum strain of approximately $40 \%$ can be seen at the region around strain of $15 \%$ to $30 \%$ strain. As for the maximum strain of approximately $20 \%$, this region where the reduction of the rate of instantaneous stress softening occurs is still observable 
but not as obvious as in the case of $40 \%$ maximum strain. Finally, this phenomenon is not observed at $10 \%$ maximum strain.

\subsubsection{Stress relaxation tensile test}

Two steps stress relaxation tensile test was held at $20 \%$ and $40 \%$ strain at $0.1 \mathrm{~s}^{-1}$ and $0.001 \mathrm{~s}^{-1}$ strain rates respectively for the duration of $3600 \mathrm{~s}$. The representative stress-strain curves from two samples are shown in Figure 15(a). As expected, the sample with higher strain rate shows higher stiffness and strength. During the relaxation, the evolution of normalized stress with respect to the holding duration is also plotted in Figure 15(b). Similarly to the work of Xia et al. and Abouzahr et al. on bulk polyurethane $[75,76]$, it appears that most stress relaxation happens before the $500 \mathrm{~s}$ of holding period, indicated by a steep curvature as shown in Figure 15(b). Sample tested under higher strain rate are further from the relaxation equilibrium path regardless of the holding strain. At lower strain rate, sample with holding strain of $40 \%$ are further from the relaxation equilibrium state than the $20 \%$ holding strain, similar to bulk polyurethane [76]. Nonetheless, sample with the higher strain rate is having similar distance from the relaxation equilibrium state independent of holding strain. The holding strain effects on the distance from the equilibrium path seem to diminish at higher strain rate. 

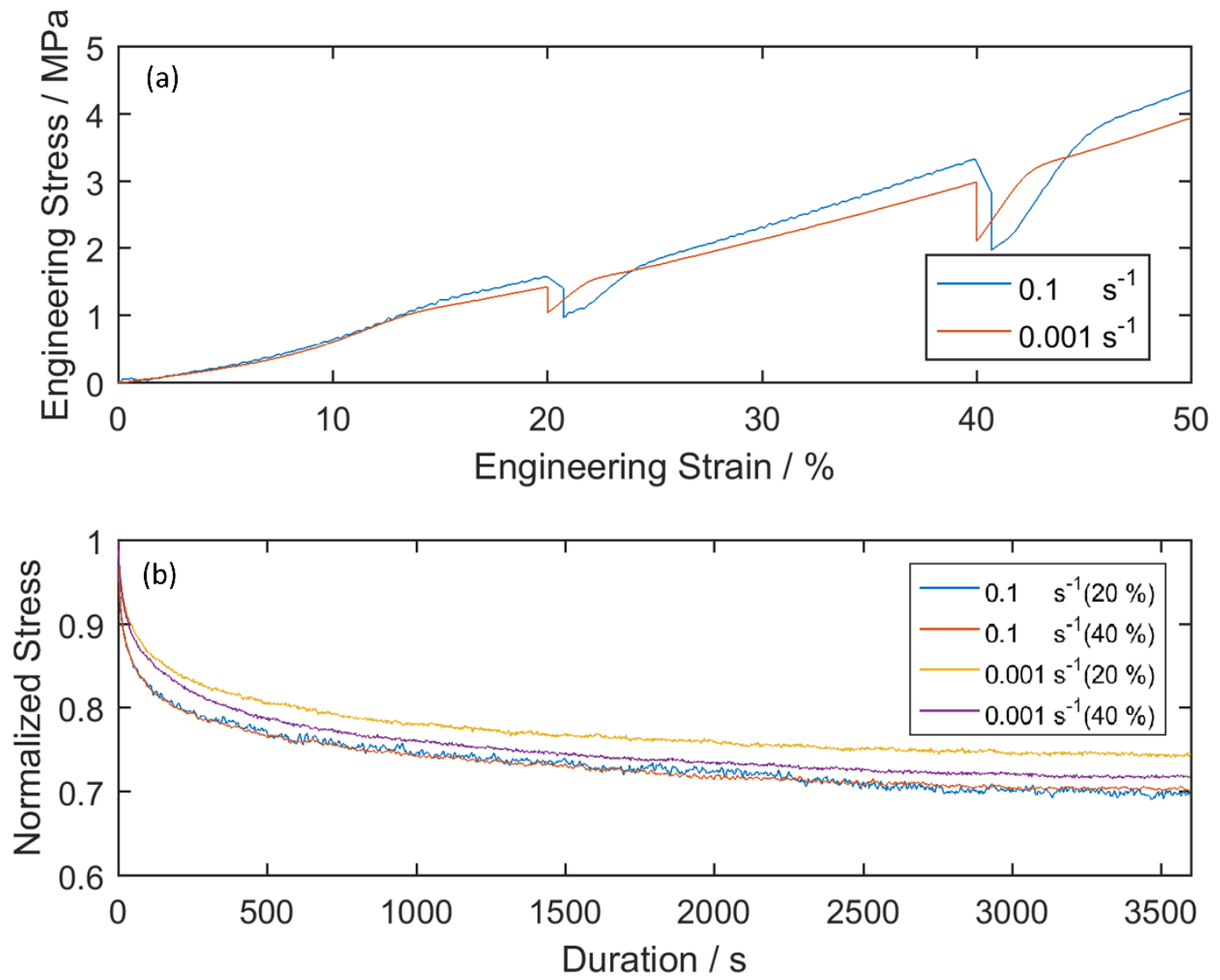

Figure. 15 Stress relaxation tensile test: Representative (a) Engineering stress-strain curve (b) Normalized stress against time 


\section{Conclusions}

In this study, the mechanical responses of highly aligned thermoplastic polyurethane elastomer microfibres were studied. The fibres were fabricated using a simple dry spinning technique assisted by an electrical field. Surface Morphology study shows that the fibres are highly aligned. Subsequently, the mechanical responses of the fibres were investigated under uniaxial monotonic, cyclic and relaxation tensile test.

In the uniaxial monotonic tensile test, the stress-strain behaviour of the fibres is nearly linear before reaching the ultimate tensile strength, which is different from the sigmoidal shaped stressstrain behaviour found in typical bulk elastomers. This shows that the mechanical property changes when bulk polyurethane is fabricated into microfibers. Higher stiffness or initial modulus is also observed when the fibres are under higher strain rate.

Inelastic mechanical responses, such as the hysteresis, stress softening and residual deformation are revealed in the uniaxial cyclic tensile test. The effect of maximum strain and strain rate on these mechanical responses was studied. Generally, hysteresis increases as the maximum strain increases. However, hysteresis remains almost constant and hysteresis loss ratio decreases as the strain rate increases. As for the stress softening, strain rate seems to have no obvious effect on it. Both hysteresis and stress softening appear to be strain rate independent.

Lastly, two steps uniaxial tensile test with two holding strains was conducted on the fibres. At higher strain rate, the distance from the relaxation equilibrium state is further than the lower strain rate. Nevertheless, similar distance from the relaxation equilibrium state is found at higher strain rate despite having different holding strain. 


\section{Acknowledgement}

The authors greatly appreciate the financial support from University of Malaya (FG010-17AFR, RP041A-17AET, PG109-2016A) and from Embassy of France in Malaysia.

\section{References}

[1] J.G. Drobny, Handbook of thermoplastic elastomers, 2 ed., William Andrew Publication, United States, 2014.

[2] S.J. Lee, D.N. Heo, M. Heo, M.H. Noh, D. Lee, S.A. Park, J.-H. Moon, I.K. Kwon, Most simple preparation of an inkjet printing of silver nanoparticles on fibrous membrane for water purification: Technological and commercial application, J. Ind. Eng. Chem., (2016) 1-6.

[3] L. Zhu, J. Dai, L. Chen, J. Chen, H. Na, J. Zhu, Design and fabrication of imidazolium ionimmobilized electrospun polyurethane membranes with antibacterial activity, J. Mater. Sci., (2016) 1-11.

[4] C. Tonda-Turo, M. Boffito, C. Cassino, P. Gentile, G. Ciardelli, Biomimetic polyurethane based fibrous scaffolds, Mater. Lett., 167 (2016) 9-12.

[5] J. Han, S. Farah, A.J. Domb, P.I. Lelkes, Electrospun rapamycin-eluting polyurethane fibers for vascular grafts, Pharm. Res., 30 (2013) 1735-1748.

[6] K. Marycz, M. Marędziak, J. Grzesiak, R. Fryczkowski, J. Laska, Polyurethane/polylactidebased electrospun nonwovens as carriers for human adipose-derived stromal stem cells and chondrogenic progenitor cells, Polym.-Plast. Technol. Eng., 55 (2016) 1897-1907. 
[7] H. Ke, M.u.H. Ghulam, Y. Li, J. Wang, B. Peng, Y. Cai, Q. Wei, Ag-coated polyurethane fibers membranes absorbed with quinary fatty acid eutectics solid-liquid phase change materials for storage and retrieval of thermal energy, Renew. Energy, 99 (2016) 1-9.

[8] X. Peng, L. Zhou, B. Jing, Q. Cao, X. Wang, X. Tang, J. Zeng, A high-performance electrospun thermoplastic polyurethane/poly(vinylidene fluoride-co-hexafluoropropylene) gel polymer electrolyte for Li-ion batteries, J. Solid State Electrochem., 20 (2015) 255-262.

[9] U. Dagli, Z. Guler, A.S. Sarac, Covalent immobilization of Tyrosinase on electrospun polyacrylonitrile/polyurethane/poly(m-anthranilic acid) nanofibers: An electrochemical impedance study, Polym.-Plast. Technol. Eng., 54 (2015) 1494-1504.

[10] J. Sheng, M. Zhang, W. Luo, J. Yu, B. Ding, Thermally induced chemical cross-linking reinforced fluorinated polyurethane/polyacrylonitrile/polyvinyl butyral nanofibers for waterproof-breathable application, RSC Adv., 6 (2016) 29629-29637.

[11] D.L. Safranski, J.M. Boothby, C.N. Kelly, K. Beatty, N. Lakhera, C.P. Frick, A. Lin, R.E. Guldberg, J.C. Griffis, Thermo-mechanical behavior and structure of melt blown shape-memory polyurethane nonwovens, J. Mech. Behav. Biomed. Mater., 62 (2016) 545-555.

[12] U. Stirna, B. Lazdin, D. Vilsone, M.J. Lopez, M.a.d.C. Vargas-Garcia, F. Sua'rez-Estrella, J. Moreno, Structure and properties of the polyurethane and polyurethane foam synthesized from castor oil polyols, J. Cell. Plast., 48 (2012) 476-488.

[13] T. Sunada, M. Kuriyagawa, T. Kawamura, K.-h. Nitta, Influence of domain structure on the mechanical properties of thermoplastic polyurethane materials, e-J Soft Mater., 7 (2011) 8-14. 
[14] A. Pedicini, R.J. Farris, Mechanical behavior of electrospun polyurethane, Polym., 44 (2003) $6857-6862$.

[15] C. Briody, B. Duignan, S. Jerrams, S. Ronan, Prediction of compressive creep behaviour in flexible polyurethane foam over long time scales and at elevated temperatures, Polym. Test., 31 (2012) 1019-1025.

[16] L. Marsavina, E. Linul, T. Voiconi, T. Sadowski, A comparison between dynamic and static fracture toughness of polyurethane foams, Polym. Test., 32 (2013) 673-680.

[17] D. Whisler, H. Kim, Experimental and simulated high strain dynamic loading of polyurethane foam, Polym. Test., 41 (2015) 219-230.

[18] O. Weißenborn, C. Ebert, M. Gude, Modelling of the strain rate dependent deformation behaviour of rigid polyurethane foams, Polym. Test., 54 (2016) 145-149.

[19] K. Lee, B. Lee, C. Kim, H. Kim, K. Kim, C. Nah, Stress-strain behavior of the electrospun thermoplastic polyurethane elastomer fiber mats, Macromol. Res., 13 (2005) 441-445.

[20] Q. Meng, J. Hu, Y. Zhu, J. Lu, Y. Liu, Morphology, phase separation, thermal and mechanical property differences of shape memory fibres prepared by different spinning methods, Smart Mater. Struct., 16 (2007) 1192-1197.

[21] N.J. Amoroso, A. D'Amore, Y. Hong, W.R. Wagner, M.S. Sacks, Elastomeric electrospun polyurethane scaffolds: The interrelationship between fabrication conditions, fiber topology, and mechanical properties, Adv. Mater., 23 (2011) 106-111.

[22] I.-C. Liao, J.B. Liu, N. Bursac, K.W. Leong, Effect of electromechanical stimulation on the maturation of myotubes on aligned electrospun fibers, Cell. Mol. Bioeng., 1 (2008) 133-145. 
[23] Y.-S. Huang, C.-C. Kuo, Y.-C. Shu, S.-C. Jang, W.-C. Tsen, F.-S. Chuang, C.-C. Chen, Highly aligned and single-layered hollow fibrous membranes prepared from polyurethane and silica blends through a two-fluid coaxial electrospun process, Macromol. Chem. Phys., 215 (2014) 879-887.

[24] E. Scholten, L. Bromberg, G.C. Rutledge, T.A. Hatton, Electrospun polyurethane fibers for absorption of volatile organic compounds from air, ACS Appl. Mater. Interfaces, 3 (2011) 39023909.

[25] C. Zandén, M. Voinova, J. Gold, D. Mörsdorf, I. Bernhardt, J. Liu, Surface characterisation of oxygen plasma treated electrospun polyurethane fibres and their interaction with red blood cells, Eur. Polym. J., 48 (2012) 472-482.

[26] S. Lee, S.K. Obendorf, Use of electrospun nanofiber web for protective textile materials as barriers to liquid penetration, Text. Res. J., 77 (2007) 696-702.

[27] J.J.L. Lee, B.C. Ang, A. Andriyana, M.I. Shariful, M.A. Amalina, Fabrication of PMMA/zeolite nanofibrous membrane through electrospinning and its adsorption behavior, J. Appl. Polym. Sci., (2017) 1-13.

[28] D. Wong, A. Andriyana, B.C. Ang, Y.R. Chan, J.J.L. Lee, A.M. Afifi, E. Verron, Surface morphology analysis and mechanical characterization of electrospun nanofibrous structure, Key. Eng. Mater., 701 (2016) 89-93.

[29] A. Homeira Emad, H. Gholamreza, Fabrication of polyurethane and thermoplastic polyurethane nanofiber by controlling the electrospinning parameters, Mater. Res. Express, 4 (2017) 105308. 
[30] D.H. Reneker, A.L. Yarin, H. Fong, S. Koombhongse, Bending instability of electrically charged liquid jets of polymer solutions in electrospinning, J. Appl. Phys., 87 (2000) 4531-4547.

[31] W.E. Teo, M. Kotaki, X.M. Mo, S. Ramakrishna, Porous tubular structures with controlled fibre orientation using a modified electrospinning method, Nanotechnol., 16 (2005) 918-924.

[32] A. Theron, E. Zussman, A.L. Yarin, Electrostatic field-assisted alignment of electrospun nanofibres, Nanotechnol., 12 (2001) 384-390.

[33] D. Li, Y. Wang, Y. Xia, Electrospinning nanofibers as uniaxially aligned arrays and layerby-layer stacked films, Adv. Mater., 16 (2004) 361-366.

[34] W.E. Teo, S. Ramakrishna, Electrospun fibre bundle made of aligned nanofibres over two fixed points, Nanotechnol., 16 (2005) 1878-1884.

[35] F. Bueche, Molecular basis for the mullins effect, J. App. Polym. Sci., 4 (1960) 107-114.

[36] W.-M. Chang, C.-C. Wang, C.-Y. Chen, The combination of electrospinning and forcespinning: Effects on a viscoelastic jet and a single nanofiber, Chem. Eng. J., 244 (2014) $540-551$.

[37] T.D. Stocco, B.V.M. Rodrigues, F.R. Marciano, A.O. Lobo, Design of a novel electrospinning setup for the fabrication of biomimetic scaffolds for meniscus tissue engineering applications, Mater. Lett., 196 (2017) 221-224.

[38] C.A. Bashur, R.D. Shaffer, L.A. Dahlgren, S.A. Guelcher, A.S. Goldstein, Effect of fiber diameter and alignment of electrospun polyurethane meshes on mesenchymal progenitor cells, Tissue Eng.: Part A, 15 (2009) 2435-2445. 
[39] S. Haider, Y. Al-Zeghayer, F.A.A. Ali, A. Haider, A. Mahmood, W.A. Al-Masry, M. Imran, M.O. Aijaz, Highly aligned narrow diameter chitosan electrospun nanofibers, J. Polym. Res., 20 (2013) 1-11.

[40] Z.X. Meng, Y.S. Wang, C. Ma, W. Zheng, L. Li, Y.F. Zheng, Electrospinning of PLGA/gelatin randomly-oriented and aligned nanofibers as potential scaffold in tissue engineering, Mater. Sci. Eng. C, 30 (2010) 1204-1210.

[41] H.-W. Tong, M. Wang, An investigation into the influence of electrospinning parameters on the diameter and alignment of poly(hydroxybutyrate-co-hydroxyvalerate) fibers, J. Appl. Polym. Sci., 120 (2011) 1694-1706.

[42] M.V. Kakade, S. Givens, K. Gardner, K.H. Lee, D.B. Chase, J.F. Rabolt, Electric field induced orientation of polymer chains in macroscopically aligned electrospun polymer nanofibers, J. Am. Chem. Soc., 129 (2007) 2777-2782.

[43] D. Wong, A. Andriyana, B.C. Ang, E. Verron, Surface morphology and mechanical response of randomly oriented electrospun nanofibrous membrane, Polym. Test., 53 (2016) 108115.

[44] J.-W. Lu, Z.-P. Zhang, X.-Z. Ren, Y.-Z. Chen, J. Yu, Z.-X. Guo, High-elongation fiber mats by electrospinning of polyoxymethylene, Macromol., 41 (2008) 3762-3764.

[45] P. Kumar, R. Vasita, Understanding the relation between structural and mechanical properties of electrospun fiber mesh through uni-axial tensile testing, J. Appl. Polym. Sci., (2017) 1-11. 
[46] F. Guo, N. Wang, L. Hou, J. Liu, L. Wang, Y. Zhao, Mechanical enhancement of bi-phasic electrospun nanofibrous films by optimizing composition and configuration, Mater. Chem. Phys., 193 (2017) 220-226.

[47] L. Jacky Jia Li, A. Andri, A. Bee Chin, H. Bertrand, V. Erwan, Electrospun PMMA polymer blend nanofibrous membrane: Electrospinability, surface morphology and mechanical response, Mater. Res. Express, 5 (2018) 065311.

[48] R. Inai, M. Kotaki, S. Ramakrishna, Deformation behavior of electrospun poly(L-lactide-coe-caprolactone) nonwoven membranes under uniaxial tensile loading, J. Polym. Sci.: Part B: Polym. Phys., 43 (2005) 3205-3212.

[49] D. Papkov, Y. Zou, M.N. Andalib, A. Goponenko, S.Z.D. Cheng, Y.A. Dzenis, Simultaneously strong and tough ultrafine continuous nanofibers, ACS Nano, 7 (2013) 33243331.

[50] M.K. Shin, S.I. Kim, S.J. Kim, S.-K. Kim, H. Lee, G.M. Spinks, Size-dependent elastic modulus of single electroactive polymer nanofibers, Appl. Phys. Lett., 89 (2006) 1-4.

[51] E.P.S. Tan, C.T. Lim, Physical properties of a single polymeric nanofiber, Appl. Phys. Lett., 84 (2004) 1603-1605.

[52] K.-S. Chen, T.L. Yu, Y.-S. Chen, T.-L. Lin, W.-J. Liu, Soft- and hard-segment phase segregation of polyester-based polyurethane, J. Polym. Res., 8 (2001) 99-109.

[53] G. Gallagher, A. Padsalgikar, E. Tkatchouk, C. Jenney, C. Iacob, J. Runt, Environmental stress cracking performance of polyether and PDMS-based polyurethanes in an in vitro oxidation model, J. Biomed. Mater. Res. B: Appl. Biomater., 00 (2016) 1-15. 
[54] R. Erdem, i. Usta, M. Akalin, O. Atak, M. Yuksek, A. Pars, The impact of solvent type and mixing ratios of solvents on the properties of polyurethane based electrospun nanofibers, Appl. Surf. Sci., 334 (2015) 227-230.

[55] L. Sun, R.P.S. Han, J. Wang, C.T. Lim, Modeling the size-dependent elastic properties of polymeric nanofibers, Nanotechnol., 19 (2008) 1-8.

[56] A.E.X. Brown, R.I. Litvinov, D.E. Discher, P.K. Purohit, J.W. Weisel, Multiscale Mechanics of Fibrin Polymer: Gel Stretching with Protein Unfolding and Loss of Water, Science, 325 (2009) 741.

[57] S.E. Szczesny, T.P. Driscoll, H.-Y. Tseng, P.-C. Liu, S.-J. Heo, R.L. Mauck, P.-H.G. Chao, Crimped nanofibrous biomaterials mimic microstructure and mechanics of native tissue and alter strain transfer to cells, ACS Biomater. Sci. Eng., (2016).

[58] G.A. Johnson, D.M. Tramaglini, R.E. Levine, K. Ohno, N.-Y. Choi, S.L.-Y. Woo, Tensile and viscoelastic properties of human patellar tendon, J. Orthop. Res., 12 (1994).

[59] J.S. Shah, M.I.V. Jayson, W.G.J. Hampson, Mechanical implications of crimping in collagen fibres of human spinal ligaments, IMechE, 8 (1979).

[60] H.J. Qi, M.C. Boyce, Stress-strain behavior of thermoplastic polyurethanes, Mech. Mater., 37 (2005) 817-839.

[61] L. Mullins, Softening of rubber by deformation, Rubber Chem. Technol., 42 (1969) 339-362.

[62] J.T. Fan, J. Weerheijm, L.J. Sluys, High-strain-rate tensile mechanical response of a polyurethane elastomeric material, Polym., 65 (2015) 72-80. 
[63] J. Yi, M.C. Boyce, G.F. Lee, E. Balizer, Large deformation rate-dependent stress-strain behavior of polyurea and polyurethanes, Polym., 47 (2006) 319-329.

[64] C.P. Buckley, C. Prisacariu, C. Martin, Elasticity and inelasticity of thermoplastic polyurethane elastomers: Sensitivity to chemical and physical structure, Polymer, 51 (2010) 3213-3224.

[65] M. Cheng, W. Chen, Experimental investigation of the stress-stretch behavior of EPDM rubber with loading rate effects, Int. J. Solid Struct., 40 (2003) 4749-4768.

[66] E.M. Christenson, J.M. Anderson, A. Hiltner, E. Baer, Relationship between nanoscale deformation processes and elastic behavior of polyurethane elastomers, Polym., 46 (2005) $11744-11754$.

[67] J.S. Bergstrom, M.C. Boyce, Constitutive modeling of the large strain time-dependent behavior of elastomers, J. Mech. Phys. Solids, 46 (1998) 931-954.

[68] K.K. Kar, A.K. Bhowmick, High-strain hysteresis of rubber vulcanizates over a range of compositions, rates, and temperatures, J. Appl. Polym. Sci., 65 (1997) 1429-1439.

[69] J.-N. Gorce, J.W. Hellgeth, T.C. Ward, Mechanical hysteresis of a polyether polyurethane thermoplastic elastomer, Polym. Eng. Sci., 33 (1993) 1170-1176.

[70] A.B. Chai, A. Andriyana, E. Verron, M.R. Johan, Mechanical characteristics of swollen elastomers under cyclic loading, Mater. Des., 44 (2013) 566-572.

[71] D.E. Hanson, M. Hawley, R. Houlton, K. Chitanvis, P. Rae, E.B. Orler, D.A. Wrobleski, Stress softening experiments in silica-filled polydimethylsiloxane provide insight into a mechanism for the Mullins effect, Polym., 46 (2005) 10989-10995. 
[72] G. Kraus, C.W. Childers, K.W. Rollmann, Stress softening in carbon black-reinforced vulcanizates. Strain rate and temperature effects, J. App. Polym. Sci., 10 (1966) 229-244.

[73] J. Diani, B. Fayolle, P. Gilormini, A review on the Mullins effect, Eur. Polym. J., 45 (2009) 601-612.

[74] T. Sui, N. Baimpas, I.P. Dolbnya, C. Prisacariu, A.M. Korsunsky, Multiple-length-scale deformation analysis in a thermoplastic polyurethane, Nat. Commun., 6 (2015).

[75] H. Xia, M. Song, Z. Zhang, M. Richardson, Microphase separation, stress relaxation, and creep behavior of polyurethane nanocomposites, J. App. Polym. Sci., 103 (2007) 2992-3002.

[76] S. Abouzahr, G.L. Wilkes, Structure property studies of polyester- and polyether-based MDI-BD segmented polyurethanes: Effect of one- vs. two-stage polymerization conditions, J. App. Polym. Sci., 29 (1984) 2695-2711. 